\title{
ECONOMIC MODEL-BASED CONTROLLER DESIGN FRAMEWORK FOR HYDRAULIC FRACTURING TO OPTIMIZE SHALE GAS PRODUCTION AND \\ WATER USAGE
}

\author{
A Thesis \\ by \\ KAIYU CAO
Submitted to the Office of Graduate and Professional Studies of Texas A\&M University in partial fulfillment of the requirements for the degree of
MASTER OF SCIENCE

\begin{abstract}
Chair of Committee, Joseph Sang-Il Kwon
Committee Members, Mahmoud M. El-Halwagi Kan Wu

Head of Department, $\quad$ M. Nazmul Karim
\end{abstract}

December 2019

Major Subject: Chemical Engineering

Copyright 2019 Kaiyu Cao 


\begin{abstract}
As water issues associated with hydraulic fracturing have received much attention, several optimization approaches have been developed for effective water management. However, most of them have not considered pumping schedules for hydraulic fracturing, which determine the productivity of a shale well as well as the total amount of freshwater required. Motivated by this consideration, a novel model-based control framework is proposed for hydraulic fracturing to maximize the net profit from shale gas development which simultaneously minimizes the total cost associated with water management. The framework is as follows; initially a reduced-order model and a Kalman filter are developed based on the simulation data generated from a high-fidelity hydraulic fracturing model to correlate the pumping schedule and the final fracture geometry. Then, a numerical reservoir simulator and mixed-integer nonlinear programming model are used to generate two maps describing the revenue from selling shale gas produced and cost from managing wastewater recovered, respectively. Finally, by applying a data-based dynamic inputoutput model to connect the two maps, a model predictive control system is formulated. The proposed control framework enables $62 \%$ of the generated wastewater to be reused through the application of thermal membrane distillation technology in treatment process and results in a $11 \%$ reduction in overall freshwater consumption, while maintaining the productivity of shale wells at its theoretical maximum.
\end{abstract}




\section{ACKNOWLEDGEMENTS}

Texas A\&M University is a wonderful place and the past two years have been the most fulfilling of my life.

I would like to say a heartfelt thank you to my advisor, Dr. Joseph Sang-Il Kwon, for giving me the opportunity to carry out this project as well as his great support and belief through the two years. He always gave me the right direction whenever I felt lost and I have learnt a lot from working with him. Thank you for your guidance.

Working with Prashanth Siddhamshetty, Rajib Mukherjee and Yuchan Ahn during these two years in Texas A\&M Energy Institute has been an exceptionally educational experience. Their method of study, spirit of investigation and work ethic are the ones I pursue.

I d also like to thank my committee members, Dr. Mahmoud M. El-Halwagi and Dr. Kan Wu, for their necessary help and advice.

Thanks also go to my colleagues and the department faculty and staff for making my time at Texas A\&M University a great experience. I want to say a special thank you to Xiaobo He, Yiling Luo, Pengfei Cheng and Jianping Li for being in my life and encouraging me all the time. I could not have done it without them.

Lastly, thanks to my mother and father for their love, support and patience. I am thankful that they have always been supportive of all my decisions and encourage me to try my best. Thank you for believing me. 


\section{CONTRIBUTORS AND FUNDING SOURCES}

\section{Contributors}

This work was supervised by a thesis committee consisting of Dr. Joseph Sang-Il Kwon of the Department of Chemical Engineering and Texas A\&M Energy Institute, Dr. Mahmoud M. El-Halwagi of the Department of Chemical Engineering, and Dr. Kan Wu of the Department of Petroleum Engineering.

The model developed in Section 3.2 was conducted in part by Prashanth Siddhamshetty of the Department of Chemical Engineering.

All other work conducted for the thesis was completed by the student independently.

\section{Funding Sources}

The authors gratefully acknowledge financial support from the National Science Foundation (CBET-1804407), the Artie McFerrin Department of Chemical engineering, and the Texas A\&M Energy Institute. 


\section{NOMENCLATURE}

\section{Sets}

$\begin{array}{ll}N & \{n \mid n=\text { fractured well }\} \\ S & \{s \mid s=\text { wastewater storage }\} \\ R & \{r \mid r=\text { reused water tank }\} \\ D & \{d \mid d=\text { rejected water tank }\} \\ A & \{a \mid a=\text { TMD system }\} \\ T & \{t \mid t=\text { time period }\}\end{array}$

Parameters
$V_{S}^{\text {storage_initial }}$
Initial volume of wastewater stored in wastewater storage $s, \mathrm{~kg}$
$H^{\text {time }}$
Operation time in each time period, s/day
$V_{S}^{\text {storage_max }}$
Maximum capacity of wastewater storage $s, \mathrm{~kg}$
$V_{r}^{\text {reuse_max }}$
Maximum capacity of reused water tank $r, \mathrm{~kg}$
$V_{d}^{\text {disposal_max }}$
Maximum capacity of rejected water tank $d, \mathrm{~kg}$
$B_{w b}$
Temperature-independent base value for the permeability, $\mathrm{kg} /\left(\mathrm{m}^{2} \cdot \mathrm{s} \cdot \mathrm{Pa} \cdot \mathrm{K}^{1.334}\right)$
K
Factor used to annualize the inversion, 1/year
$U C^{\text {fresh }}$
Unit cost for freshwater, $\$ / \mathrm{kg}$
UOC disposal
Unit operating cost for disposal unit, \$/kg
UTC $C^{\text {well_storage }} \quad$ Unit transportation cost for wastewater from fractured well to wastewater storage, $\$ / \mathrm{kg}$




\begin{tabular}{|c|c|}
\hline UTC $C^{\text {storage_treatment }}$ & $\begin{array}{l}\text { Unit transportation cost for wastewater from wastewater storage } \\
\text { to TMD system, } \$ / \mathrm{kg}\end{array}$ \\
\hline UTC treatment_reuse $^{\text {tren }}$ & $\begin{array}{l}\text { Unit transportation cost for treated water from TMD system to } \\
\text { reused water tank, } \$ / \mathrm{kg}\end{array}$ \\
\hline UTC ${ }^{\text {treatment_disposal }}$ & $\begin{array}{l}\text { Unit transportation cost for treated water from TMD system to } \\
\text { rejected water tank, } \$ / \mathrm{kg}\end{array}$ \\
\hline$F C^{\text {storage }}$ & Fixed charge for storage unit, $\$$ \\
\hline$V C^{\text {storage }}$ & Variable charge for storage unit, $\$ / \mathrm{kg}$ \\
\hline$F C^{\text {reuse }}$ & Fixed charge for reuse unit, $\$$ \\
\hline$V C^{\text {reuse }}$ & Variable charge for reuse unit, $\$ / \mathrm{kg}$ \\
\hline$F C^{\text {disposal }}$ & Fixed charge for disposal unit, $\$$ \\
\hline$V C^{\text {disposal }}$ & Variable charge for disposal unit, $\$ / \mathrm{kg}$ \\
\hline UP reuse & Unit profit from reusing water, $\$ / \mathrm{kg}$ \\
\hline$M_{\text {prop }}$ & Total amount of injected proppant for the shale reservoir, kg \\
\hline$M_{\text {prop,f }}$ & Total amount of injected proppant for one fracture, $\mathrm{kg}$ \\
\hline$A_{\text {section }}$ & Drainage area for the shale reservoir, $\mathrm{m}^{2}$ \\
\hline$W_{\text {opt }}$ & Minimum average propped fracture width required, $\mathrm{m}$ \\
\hline$H_{r}$ & Reservoir thickness, $\mathrm{m}$ \\
\hline$\phi$ & Proppant bank porosity \\
\hline$t_{b}$ & Gas breakthrough time, day \\
\hline$r_{0}$ & Market price of shale gas, $\$ /$ MMBTU \\
\hline$I$ & Money discount rate \\
\hline$c$ & Time constant, 1 /day \\
\hline
\end{tabular}




\title{
Variables
}

\author{
$F_{n, t}^{\text {well_out }}$ \\ Wastewater flowrate leaving fractured well $n$ in time period $t$, \\ $\mathrm{kg} / \mathrm{s}$ \\ $F_{s, t}^{\text {storage_in }}$ \\ flowrate entering wastewater storage $s$ in time period $t, \mathrm{~kg} / \mathrm{s}$ \\ $F_{S, t}^{\text {storage_out }}$ \\ flowrate leaving wastewater storage $s$ in time period $t, \mathrm{~kg} / \mathrm{s}$ \\ $F_{a, t}^{\text {treatment_in }}$ \\ flowrate entering TMD system $a$ in time period $t, \mathrm{~kg} / \mathrm{s}$ \\ $F_{r, t}^{r e u s e \_i n}$ \\ flowrate entering reused water tank $a$ in time period $t, \mathrm{~kg} / \mathrm{s}$ \\ $F_{d, t}^{\text {disposal_in }}$ \\ flowrate entering rejected water tank $a$ in time period $t, \mathrm{~kg} / \mathrm{s}$ \\ $M_{S, t}^{\text {storage_in }}$ \\ TDS mass flowrate entering wastewater storage $s$ in time period $t$, \\ $\mathrm{kg} / \mathrm{s}$ \\ $M_{a, t}^{\text {treatment_in }}$ \\ TDS mass flowrate entering TMD system $a$ in time period $t, \mathrm{~kg} / \mathrm{s}$ \\ $f f_{n, s, t}^{\text {well_storage }}$ \\ Segregated flowrate from fractured well $n$ to wastewater storage $s$ \\ in time period $t, \mathrm{~kg} / \mathrm{s}$ \\ $f f_{s, a, t}^{\text {storage_treatment }}$ \\ Segregated flowrate from wastewater storage $s$ to TMD system $a$ \\ in time period $t, \mathrm{~kg} / \mathrm{s}$

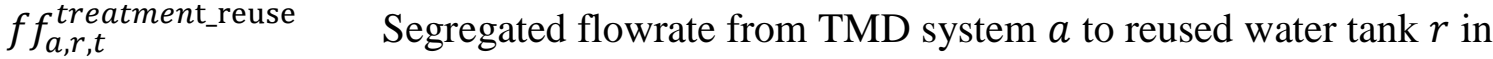 \\ time period $t, \mathrm{~kg} / \mathrm{s}$ \\ $f f_{a, d, t}^{\text {treatment_disposal }}$ \\ Segregated flowrate from TMD system $a$ to rejected water tank $d$ \\ in time period $t, \mathrm{~kg} / \mathrm{s}$

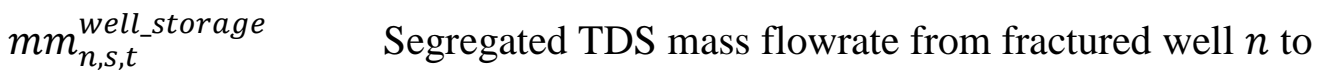 \\ wastewater storage $s$ in time period $t, \mathrm{~kg} / \mathrm{s}$ \\ $m m_{s, a, t}^{\text {storage_treatment }}$ \\ Segregated TDS mass flowrate from wastewater storage $s$ to \\ TMD system $a$ in time period $t, \mathrm{~kg} / \mathrm{s}$
}




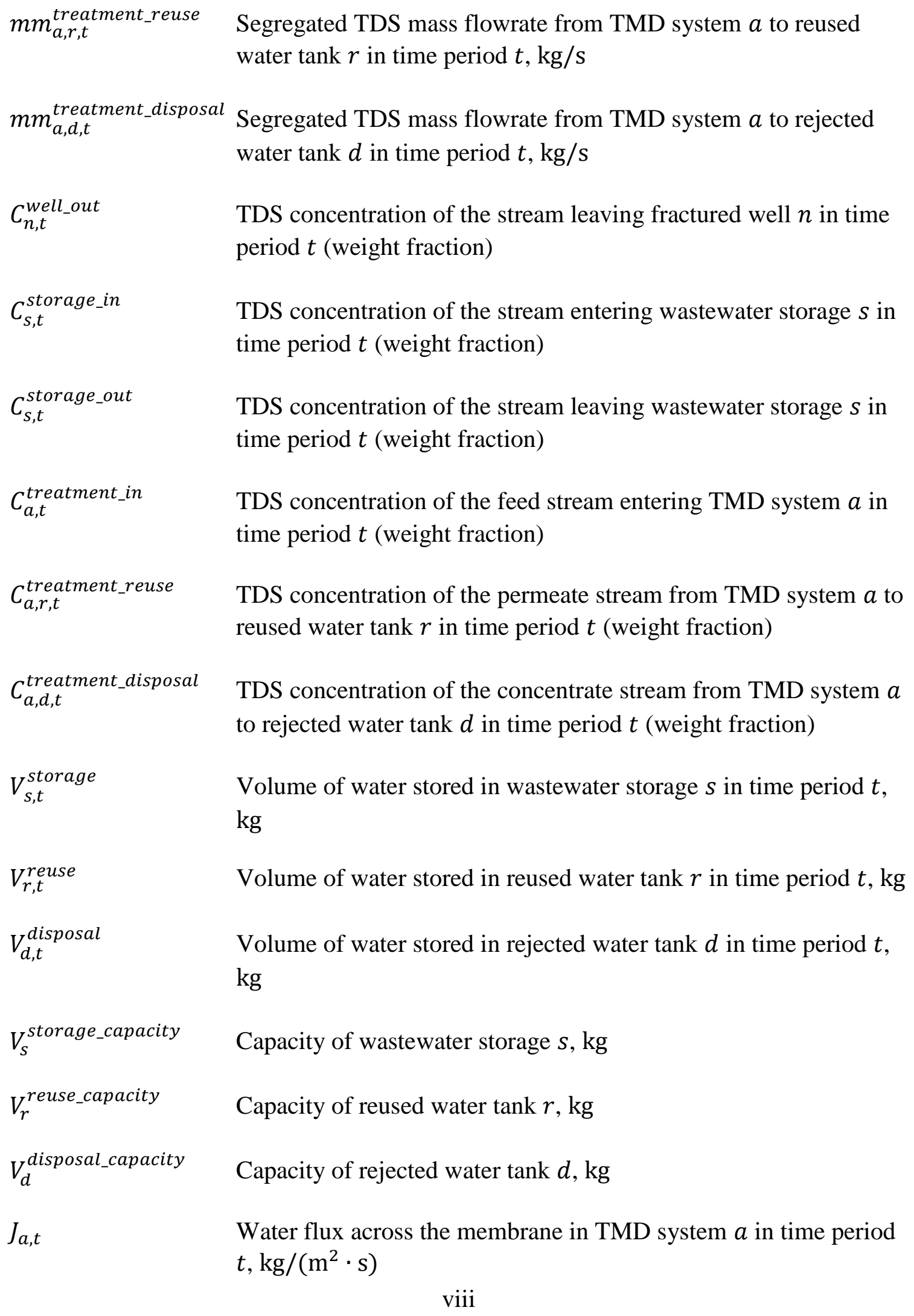




\begin{tabular}{|c|c|}
\hline$B_{w}$ & Membrane permeability, $\mathrm{kg} /\left(\mathrm{m}^{2} \cdot \mathrm{s} \cdot \mathrm{pa}\right)$ \\
\hline$P_{\text {feed }}^{v}$ & Water vapor pressure of the feed stream, $\mathrm{Pa}$ \\
\hline$P_{\text {perm }}^{v}$ & Water vapor pressure of the permeate stream, $\mathrm{Pa}$ \\
\hline$\gamma_{w, \text { feed }, a, t}$ & $\begin{array}{l}\text { Activity coefficient of water in the feed stream entering TMD } \\
\text { system } a \text { in time period } t\end{array}$ \\
\hline$x_{w, f e e d, a, t}$ & $\begin{array}{l}\text { Mole fraction of water in the feed stream entering TMD system } a \\
\text { in time period } t\end{array}$ \\
\hline$x_{N a C l, f e e d, a, t}$ & $\begin{array}{l}\text { Mole fraction of } \mathrm{NaCl} \text { in the feed stream entering TMD system } a \\
\text { in time period } t\end{array}$ \\
\hline$T_{m}$ & Membrane average temperature, $\mathrm{K}$ \\
\hline$T_{m, \text { feed }}$ & Temperature of the feed stream on the membrane, $\mathrm{K}$ \\
\hline$T_{m, p e r m}$ & Temperature of the permeate stream on the membrane, $\mathrm{K}$ \\
\hline$T_{b, f e e d}$ & Bulk temperature of the feed stream, $\mathrm{K}$ \\
\hline$T_{b, p e r m}$ & Bulk temperature of the permeate stream, $\mathrm{K}$ \\
\hline$A_{m, a, t}$ & Required membrane area in TMD system $a$ in time period $t, \mathrm{~m}^{2}$ \\
\hline$A_{m, a}$ & Required membrane area in TMD system $a, \mathrm{~m}^{2}$ \\
\hline$\zeta_{a, t}$ & Water recovery in TMD system $a$ in time period $t$ \\
\hline$v_{a, t}$ & Recycle ratio in TMD system $a$ in time period $t$ \\
\hline Cost $t_{a, t}^{\text {treatment }}$ & $\begin{array}{l}\text { Annualized operating cost for TMD system } a \text { in time period } t \text {, } \\
\text { \$/year }\end{array}$ \\
\hline CapCOST $T_{a, t}^{\text {treatment }}$ & $\begin{array}{l}\text { Annualized capital cost for TMD system } a \text { in time period } t \\
\$ / \text { year }\end{array}$ \\
\hline Cost ${ }^{\text {treatment }}$ & 1 operating cost for TMD system, \$/year \\
\hline
\end{tabular}


Cost Total disposal $^{\text {dispost }}$ \$/year

TransCost ${ }^{\text {well_storage }} \quad$ Total transportation cost for wastewater from fractured wells to wastewater storages, \$/year

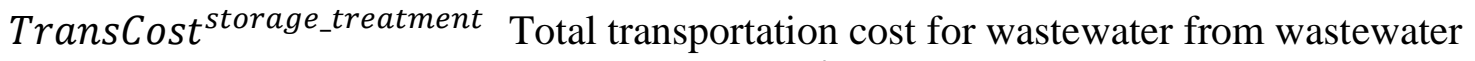
storages to TMD system, \$/year

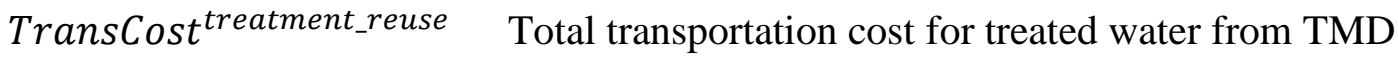
system to reused water tanks, \$/year

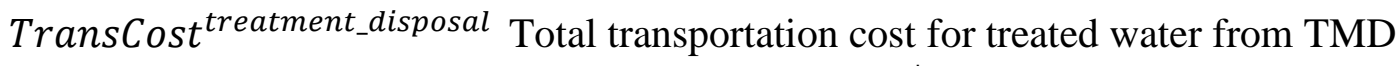
system to rejected water tanks, \$/year

TransCost ${ }^{\text {total }} \quad$ Total transportation cost, \$/year

CapCost treatment Total capital cost for TMD system, \$/year

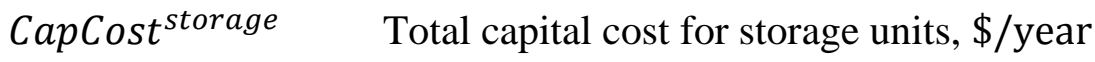

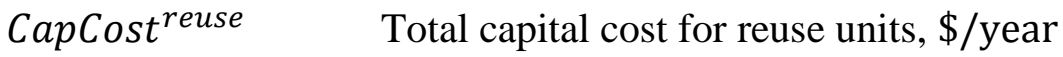

CapCost disposal Total capital cost for disposal units, \$/year

Profit ${ }^{\text {reuse }} \quad$ Total profit from reusing water, \$/year

TAC Total annual cost, \$/year

TFC Total cost for freshwater, \$/year

$n_{c} \quad$ Optimum number of wells subject to given fracturing resources

$n_{r} \quad$ Optimum number of fractures per well subject to given fracturing resources

$x_{f} \quad$ Optimum propped fracture half-length subject to given fracturing resources

$n_{f} \quad$ Total number of fractures in the shale reservoir

$A_{\text {subsection }} \quad$ Drainage area for one fracture, $\mathrm{m}^{2}$

J Productivity of the shale reservoir 


\begin{tabular}{|c|c|}
\hline$J_{D, f}$ & Dimensionless productivity index for one fracture \\
\hline$A_{r}$ & Aspect ratio of one fracture \\
\hline$I_{x}$ & Penetration ratio of one fracture \\
\hline$l_{f}$ & Total fracture length in the shale reservoir, $\mathrm{m}$ \\
\hline$h_{e q}$ & Equilibrium proppant bank height, $\mathrm{m}$ \\
\hline$W_{\text {avg,target }}$ & Desired average fracture width at the end of pumping, $\mathrm{m}$ \\
\hline$Q_{0}$ & Flowrate of injected fracturing fluid, $\mathrm{kg} / \mathrm{s}$ \\
\hline$C_{0}$ & $\begin{array}{l}\text { Proppant concentration of injected fracturing fluid (weight } \\
\text { fraction) }\end{array}$ \\
\hline$W_{a v g, x_{f}}$ & $\begin{array}{l}\text { Average fracture width at the end of pumping over the optimum } \\
\text { fracture half-length, } m\end{array}$ \\
\hline$W_{0}$ & Fracture width at the wellbore, $\mathrm{m}$ \\
\hline$L$ & Fracture length, $\mathrm{m}$ \\
\hline$Q_{n}^{\text {injected }}$ & $\begin{array}{l}\text { Total volume of injected fracturing fluid water for fractured well } \\
n, \mathrm{BBL}\end{array}$ \\
\hline$Q^{\text {injected }}$ & $\begin{array}{l}\text { Total volume of injected fracturing fluid for on fractured well, } \\
\text { BBL }\end{array}$ \\
\hline$T R S G$ & $\begin{array}{l}\text { Total revenue from shale gas production for one fractured well, } \\
\text { MM }\end{array}$ \\
\hline$\overline{q_{0}}$ & Shale gas production rate, $\mathrm{FT}^{3} /$ day \\
\hline$L_{f}$ & Propped fracture half-length, $\mathrm{m}$ \\
\hline$M_{\text {prop,frac }}$ & Total amount of injected proppant for one fracture, $\mathrm{kg}$ \\
\hline$Q_{n, t}^{\text {well_out }}$ & Cumulative volume of generated wastewater, $\mathrm{kg}$ \\
\hline
\end{tabular}


$y_{n, t}^{\text {well_out }}$

\section{Binary variables}

$y_{S}^{\text {storage }}$

$y_{r}^{r e u s e}$ $y_{d}^{\text {disposal }}$
Cumulative recovery ratio of generated wastewater

Used to model the existence of the wastewater storage $s$
Used to model the existence of the reused water tank $r$
Used to model the existence of the rejected water tank $d$ 


\section{TABLE OF CONTENTS}

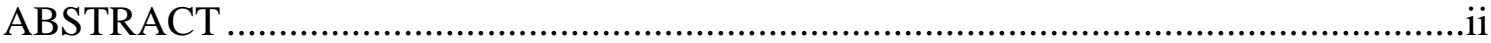

ACKNOWLEDGEMENTS …………................................................................... ii

CONTRIBUTORS AND FUNDING SOURCES.........................................................iv

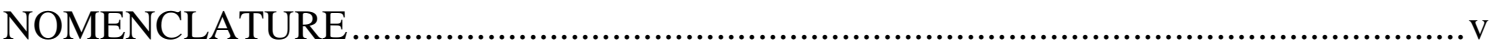

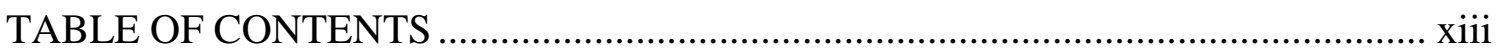

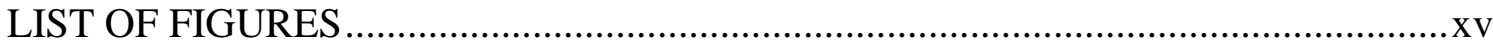

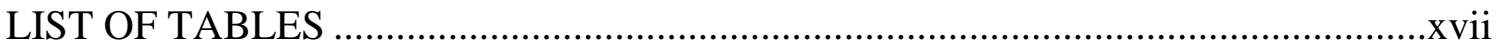

1. INTRODUCTION

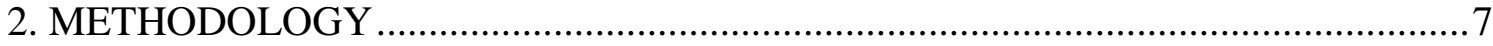

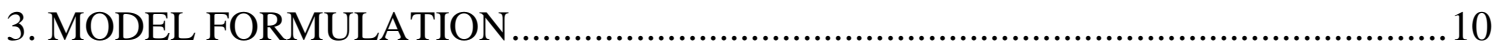

3.1. Optimization Modeling for Wastewater Management..........................................10

3.1.1. Balance and Constraint............................................................................... 11

3.1.2. Thermal Membrane Distillation (TMD) Model .............................................16

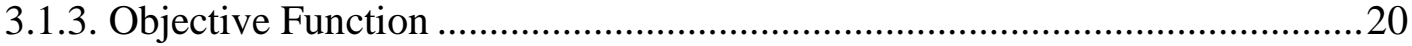

3.2. Model Predictive Control for Hydraulic Fracturing ..............................................23

3.2.1. Section-based Optimization Model ................................................................24

3.2.2. Reduced-order Model and Kalman filter....................................................26

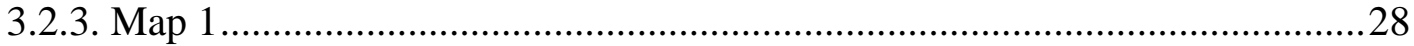

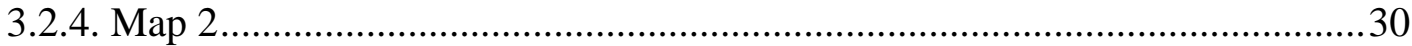

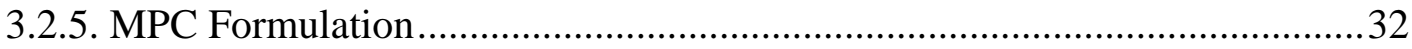

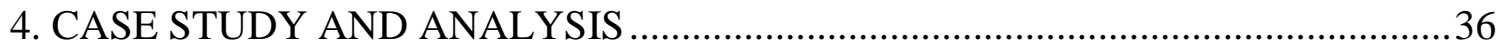

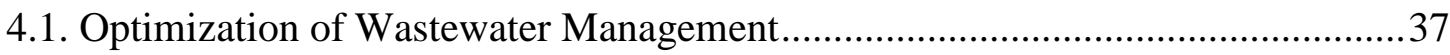

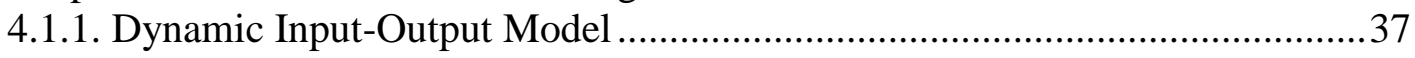

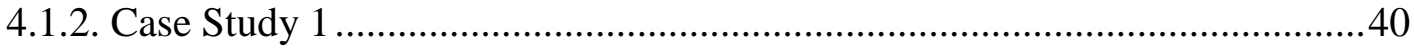

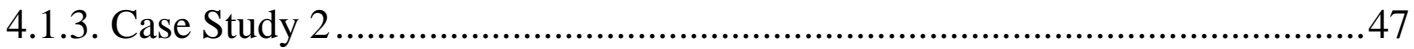

4.2. Modeling of Hydraulic Fracture .....................................................................50

xiii 
4.3. Proposed Mapping-based Control of Hydraulic Fracturing ................................54

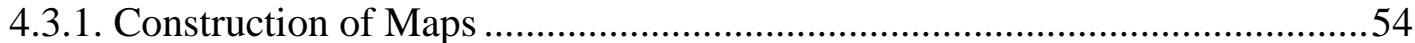

4.3.2. Model-based Feedback Controller ..................................................................56

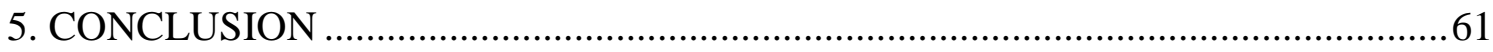

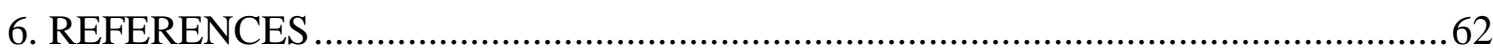

APPENDIX A SECTION-BASED OPTIMIZATION MODEL ...................................69

APPENDIX B DATA-BASED DYNAMIC INPUT-OUTPUT MODEL ......................70

APPENDIX C WASTEWATER MANAGEMENT MODEL ......................................74

APPENDIX D ONE-WING HYDRAULIC FRACTURE MODEL ............................79

xiv 


\section{LIST OF FIGURES}

Figure 2.1 Schematic flow diagram for shale gas development

Figure 2.2 Algorithmic diagram for shale gas development ..................................... 8

Figure 3.1 Schematic flow diagram for the optimization model of wastewater management.

Figure 3.2 Schematic diagram for TMD system

Figure 3.3 Schematic diagram for MPC system

Figure 4.1 Cumulative recovery ratio of the wastewater recovered over the first year ...39

Figure 4.2 TDS concentration profile of the wastewater recovered over the first year ...39

Figure 4.3 Flowrate profile of the wastewater recovered over the first year.....

Figure 4.4 TDS weight fraction profile of the wastewater recovered over the first year.42

Figure 4.5 Comparison of flowrate of the streams entering and leaving the storage..... .45

Figure 4.6 Comparison of TDS weight fraction of the streams entering and leaving the storage.

Figure 4.7 Flowrate of the feed, permeate and concentrate streams around TMD system

Figure 4.8 Percentage of the reused and rejected water around TMD system. 47

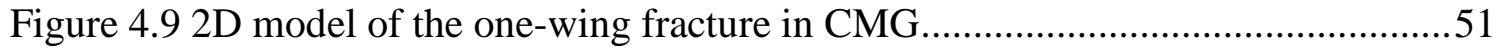

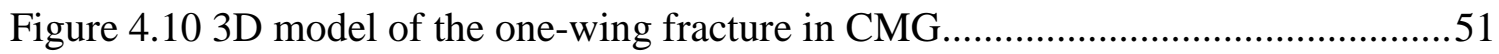

Figure 4.11 Cumulative gas production for $120 \mathrm{~m}$ one-wing fracture ..........................52

Figure 4.12 Gas flowrate for $120 \mathrm{~m}$ one-wing fracture...............................................53

Figure 4.13 Pressure distribution after 8, 12, 16 months production for $120 \mathrm{~m}$ onewing fracture

Figure 4.14 Map from optimization model of wastewater management for different scenarios 
Figure 4.15 Map obtained from CMG reservoir simulation of one-wing fracture for different scenarios ...........................................................................................56

Figure 4.16 Optimal pumping schedule for shale gas production....................................57

Figure 4.17 Proppant bank height profile during hydraulic fracturing process ...............58

Figure B. 1 Cumulative recovery ratio of flowback water.............................................72

Figure B. 2 TDS concentration profile of flowback water.............................................72 


\section{LIST OF TABLES}

Page

Table 4.1 Comparison of computational statistics in Case 1 . .......................................43

Table 4.2 Design variables and costs for wastewater management in Case 1..............43

Table 4.3 Design variables and costs for wastewater management in Case 2. ...............48

Table 4.4 Closed-loop simulation results for one horizontal well. ................................59

Table A Optimal design parameters used in shale reservoir ....................................69

Table B. 1 Water use and flowback water collection associated with hydraulic fracturing of shale gas wells.

Table B. 2 Concentration of total dissolved solids (TDS) in flowback water at 19 locations.

Table B. 3 Flowrate and TDS weight fraction profiles for given injected fracturing fluid volume.

Table C. 1 Parameters and cost-coefficients used in the TMD system and wastewater management

Table C. 2 Design variables and costs for wastewater management in Case 1...............75

Table C. 3 Flowrate (kg/s) and TDS weight fraction of the streams in Case $1 \ldots \ldots \ldots \ldots \ldots . . . .76$

Table C. 4 Design variables and costs for wastewater management in Case 2 .............. 77

Table C. 5 Flowrate (kg/s) and TDS weight fraction of the streams in Case 2..............78

Table D. 1 Parameters used for one-wing fracture in Marcellus Shale..........................79

Table D. 2 Shale gas production and corresponding revenue for the first production year. 


\section{INTRODUCTION*}

Shale gas is an indispensable resource to satisfy the global energy demand and it has resulted in an increase in the total energy production of the United States. As reported, the production from shale gas is the main contributor to the growth of natural gas production, being expected to account for nearly two-thirds of the total US production by 2040. ${ }^{1}$ The exploration and development of shale gas will possibly allow the United States to become energy independent by $2026 .{ }^{1}$ This rapid growth in shale gas production would not have happened without the continued technological advancement and improvement. Since shale gas is characterized as an unconventional resource due to ultra-low permeability of the rock formation, it is extremely difficult and costly to extract gas from shale rock in the past decades. ${ }^{2}$ Recently, the combined use of horizontal drilling and hydraulic fracturing technologies has ramped up shale gas production and made it economically viable to develop unconventional reservoirs. The horizontal drilling makes it accessible to more targeted hydrocarbon zones from one surface location, which decreases the capital investment while improving the efficiency of the exploitation process. ${ }^{3}$ The hydraulic fracturing helps create high conductivity pathways for gas extraction and enhance formation permeability, which in turn increases the overall productivity of the fractured wells.

\footnotetext{
*Reprinted with permission from "Economic model-based controller design framework for hydraulic fracturing to optimize shale gas production and water usage" by Cao, K.; Siddhamshetty, P.; Ahn, Y.; Mukherjee, R. and Kwon, J. S. 2019. Ind. Eng. Chem. Res., 2019. Copyright 2019 American Chemical Society.
} 
Despite the economic benefit of horizontal drilling and hydraulic fracturing technology, the concerns about the associated water issues have been growing. On average, about 3-6 million gallons of freshwater are used to complete a typical well., ${ }^{4}$ Nearly $10 \%$ of this freshwater is used in the drilling process while the remaining $90 \%$ is required for hydraulic fracturing operation, in which the injected water is mixed with proppant (most often sand) and chemical additives to make up the fracturing fluid for propagation of fractures. ${ }^{6}$ Since many sites can contain several well pads which allow multiple horizontal wells to be drilled and fracking process takes only 2-3 days, a serious problem is that a considerable amount of freshwater must be supplied within a relatively short time. ${ }^{7}$ Another issue that appears in the post-fracturing process is water contamination. After hydraulic fracturing, a certain amount of the injected fracturing fluid flows back to the surface as wastewater, containing high concentrations of various contaminants such as the total dissolved solids (TDS), metals, total suspended solids (TSS), naturally occurring radioactive material (NORM), organics, and hydrocarbons. ${ }^{6,8}$ Since the conventional disposal option of deep well injection is not necessarily available near the drilling sites and fracturing fluid becomes more tolerant of contaminants, the demand for treatment of wastewater for recycle and reuse has been recently increased. ${ }^{9}$ In general, the quality of wastewater generated from hydraulic fracturing can be determined by the amount of TDS per liter of water. ${ }^{10,11}$ Removal of the TDS can be achieved using several available treatment technologies including: reverse osmosis (RO), membrane distillation (MD), evaporation and crystallization. ${ }^{9}{ }^{12-17}$ However, selection of the proper technology depends on the TDS concentration in the wastewater, required purification 
level for recycle and reuse, operating condition in the hydraulic fracturing process and capacity of the treatment technology. Since the characteristics of the shale formation vary from region to region, the recovery ratio, TDS concentration and flowrate of the generated wastewater can be significantly different. In addition, the differences in state regulatory policies and economic factors may also affect the strategy for effective water management. Thus, with the difficulty in supplying sufficient freshwater to drilling sites and the instability of wastewater treatment, developing an environmentally sustainable and economically viable water management plan along with optimizing production is crucial.

In this regard, several strategies to effectively manage water in shale gas development have been developed using optimization techniques. ${ }^{5,-10,18,19}$ Yang et al. developed a two-stage stochastic mixed-integer linear programming (MILP) model for operational scheduling problem while minimizing the freshwater consumption and the total cost in the water cycle. ${ }^{8}$ To consider the decisions on strategic design, they extended the previous work and presented a comprehensive MILP model for capital investment decisions as well as the scheduling for long-term operation. ${ }^{9}$ Gao and You proposed a novel mixed-integer linear fractional programming (MILFP) model and associated global optimization algorithm for optimal design of water supply networks. ${ }^{10}$ Lira-Barragan et al. expanded the commonly used optimization framework to include the uncertainties related to the amount of injected freshwater and generated wastewater. ${ }^{5}$ Lopez Diaz et al. developed a multi-objective optimization model for water networks, which presents the tradeoffs between the economic and environmental objectives by minimizing the total annual cost and maximizing the removal of pollutants. ${ }^{19}$ Oke et al. developed a mixed- 
integer nonlinear programming (MINLP) model by applying continuous time scheduling formulations and detailed membrane distillation models, which simultaneously optimizes the water and energy consumption in the integrated water and membrane distillation network. ${ }^{18}$ However, these studies did not consider hydraulic fracturing as a dynamic process, in which the flowrate of fracturing fluid, some of which contains freshwater, should be determined by a controller to maximize productivity of the fractured wells. In hydraulic fracturing operation, the pumping schedule, including the flowrate and the proppant concentration of the injecting fracturing fluid, is critical. It determines the volume of freshwater needed for blending and directly affects the proppant distribution inside the created fractures, which influences the fracture conductivity and thus the production rate of shale gas. Over the last few decades, several efforts have been made to obtain the optimal pumping schedule while achieving the uniform proppant concentration and the prescribed fracture geometry at the end of pumping ${ }^{2028}$ Specifically, Siddhamshetty et al. developed a model-based feedback control system which can compute the optimal pumping schedule to achieve a uniform proppant bank height over the optimal fracture length at the end of pumping. ${ }^{23}$ However, this pumping schedule was obtained neglecting the environmental and the economic impacts of the water management.

Recently, Etoughe et al. proposed a new framework integrating the optimization work of water management into the model-based pumping schedule design of hydraulic fracturing, which minimizes the freshwater consumption as well as the total annual cost from water management and reduces the negative environmental impact. ${ }^{29}$ In their work, the feedback control system developed by Siddhamshetty et al. was used to determine the 
optimal pumping schedule with reduced amount of freshwater, which maximizes the productivity of the fractured well. ${ }^{23}$ Then, a MINLP model was developed to determine the corresponding optimal water management strategy and mitigate the environmental toxicity by treating the flowback water through membrane distillation technology. Although this study provided an idea that the required freshwater consumption can be reduced by manipulating the pumping schedule, the resultant optimal water management could have negative impacts on the productivity, which was not considered due to the open-loop nature of the developed framework. That is, injecting less water, which is not sufficient to achieve the optimal fracture geometry at the end of pumping, may be beneficial from the water management perspective, while the final fracture geometry may result in a decrease in productivity. On the contrary, if the optimal fracture geometry is desired, which requires more freshwater in hydraulic fracturing operation, there will be an increase in the total cost from water management. Thus, these two processes are negatively correlated and it is imperative to develop a closed-loop framework accounting for the trade-off between the water management cost and the shale gas production.

Motivated by these considerations, the focus of this study is to propose a novel controller design framework for hydraulic fracturing while considering the impact of water management. To establish the closed-loop control system, a mapping-based technique is proposed. In the modeling of wastewater management, a dynamic inputoutput model is developed based on field data to establish the correlation between pumping schedule (i.e., volume of injected freshwater) and characteristics of recovered wastewater (i.e., flowrate and TDS concentration). Then, a MINLP optimization model is 
developed with the incorporation of a thermal membrane distillation (TMD) model. After solving the optimization problem with multiple operating conditions (i.e., different flowrate and TDS concentration profiles of generated wastewater), one map representing the relationship between the total wastewater management cost and the total volume of injected freshwater is obtained offline. In the modeling of hydraulic fractures, the reservoir simulation software from Computer Modeling Group Ltd. (CMG) is used to generate the shale gas production profile based on the final fracture geometry. By running CMG with multiple fracture geometries and taking into account the selling price of shale gas, another map representing the relationship between the total revenue from shale gas production and the final fracture geometry is also obtained offline. Then, a section-based optimization method is used to determine the key design parameters for the modeling of shale reservoir. Finally, applying the two maps to the feedback control system for hydraulic fracturing and considering the purchase of freshwater to make up the fracturing fluid, a new model predictive control (MPC) formulation is developed to determine the optimal pumping schedule which maximizes the net profit from shale gas development by simultaneously considering the revenue from shale gas production and the cost from water management (i.e., cost from purchasing freshwater and managing wastewater).

This paper is organized as follows. Section 2 provides detailed information about the schematic diagram of the integrated control framework. The developed mathematical model for the wastewater management and the formulations for the MPC system are presented in Section 3. In Section 4, the results and discussion are described. Finally, several conclusions are given in Section 5. 


\section{METHODOLOGY*}

Figure 2.1 shows a schematic flow diagram constructed to represent the shale gas development, which can be divided into two subsections. Figure 2.2 represents the algorithmic diagram of the proposed control framework.

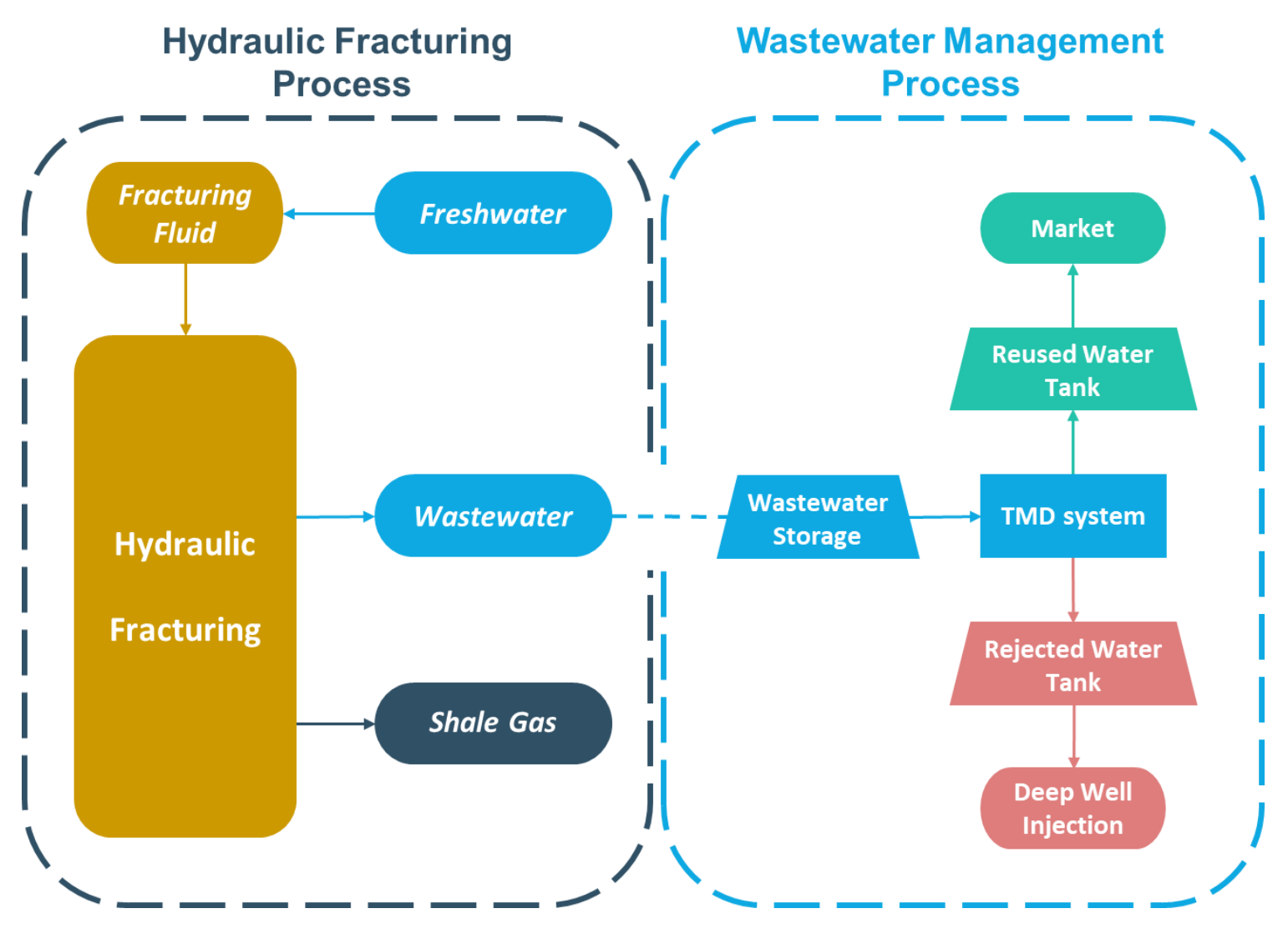

Figure 2.1 Schematic flow diagram for shale gas development

\footnotetext{
*Reprinted with permission from "Economic model-based controller design framework for hydraulic fracturing to optimize shale gas production and water usage" by Cao, K.; Siddhamshetty, P.; Ahn, Y.; Mukherjee, R. and Kwon, J. S. 2019. Ind. Eng. Chem. Res., 2019. Copyright 2019 American Chemical Society.
} 


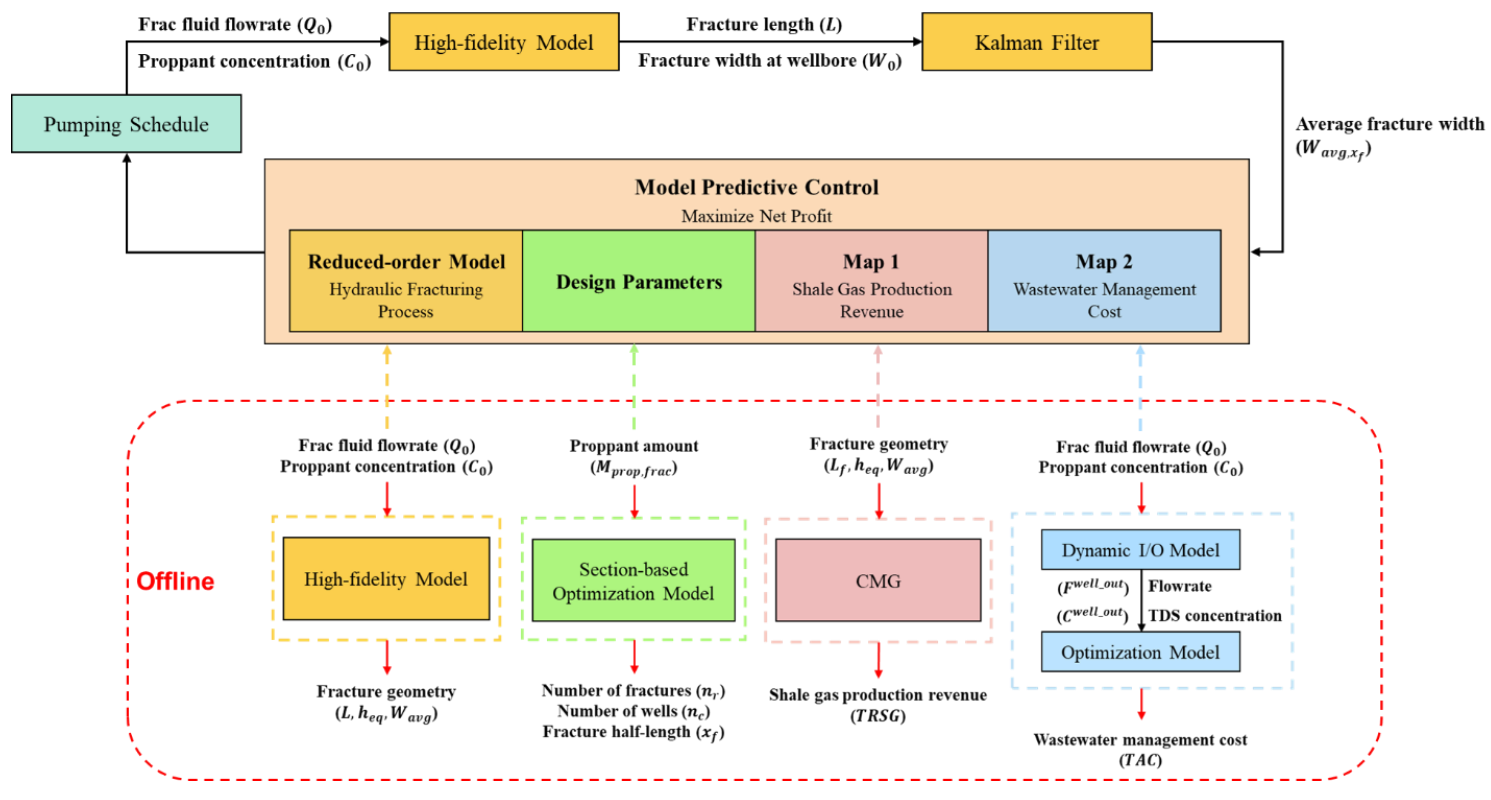

Figure 2.2 Algorithmic diagram for shale gas development

First, in the modeling of hydraulic fracturing, the control framework is developed by extending the feedback control system as designed by Siddhamshetty et al. ${ }^{23}$ With the reduced-order model (ROM) and Kalman filter generated based on high-fidelity simulation data, the final fracture geometry is determined based on the pumping schedule (i.e., flowrate and proppant concentration of injected fracturing fluid). Using CMG software and considering the selling price of shale gas, the gas production profile and the corresponding revenue are obtained. Second, in the modeling of wastewater management, the TMD technology is considered for wastewater treatment. Then, a mathematical model based on the integrated water and TMD network is developed to minimize the cost associated with the wastewater management strategy. To connect these two processes, a dynamic input-output model is proposed to establish the correlation between the pumping schedule (i.e., volume of injected freshwater) and characteristics of the generated 
wastewater (i.e., flowrate and TDS concentration), which are the inputs for the simulation of hydraulic fracturing and the modeling of wastewater management respectively. Assuming that the freshwater used to make up the injected fracturing fluid is purchased from market, the freshwater cost is also obtained based on the pumping schedule (i.e., volume of injected freshwater). Thus, along with the section-based optimization model which is used to determine key design parameters for the modeling of shale reservoir (i.e., number of wells, number of fractures and fracture half-length), a closed-loop MPC system is designed to maximize the net profit from the shale gas development by manipulating the pumping schedule. 


\section{MODEL FORMULATION*}

\subsection{Optimization Modeling for Wastewater Management}

In this section, the superstructure for the wastewater management is developed, as shown in Figure 3.1.

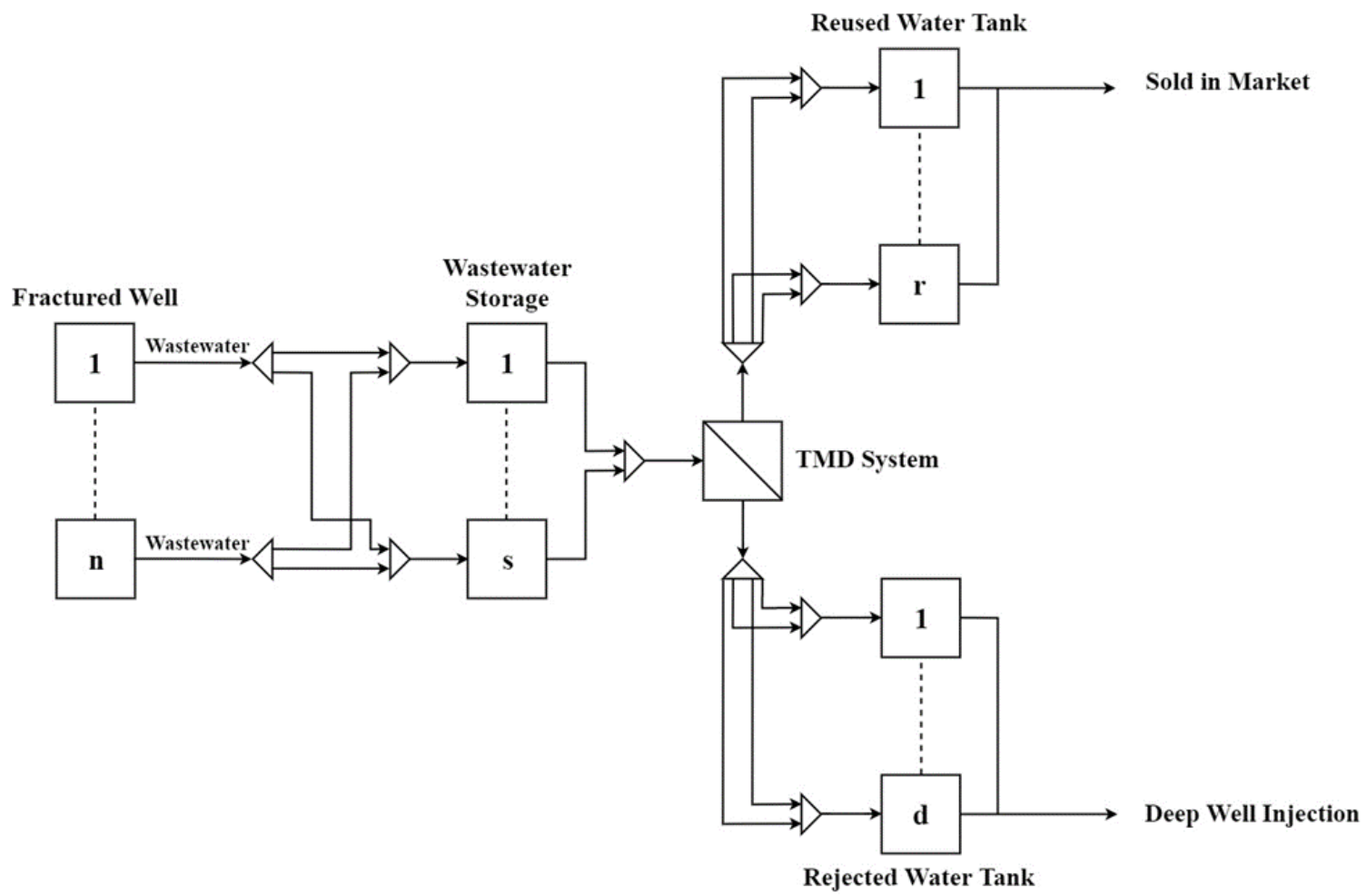

Figure 3.1 Schematic flow diagram for the optimization model of wastewater management

A set of $(N)$ fractured wells, $(S)$ storage units, $(R)$ reuse units, $(D)$ disposal units and one $(A=1)$ treatment unit are included in this network, and the problem is addressed *Reprinted with permission from "Economic model-based controller design framework for hydraulic fracturing to optimize shale gas production and water usage" by Cao, K.; Siddhamshetty, P.; Ahn, Y.; Mukherjee, R. and Kwon, J. S. 2019. Ind. Eng. Chem. Res., 2019. Copyright 2019 American Chemical Society. 
over a time horizon which is divided into (T) identical time intervals. The subscripts $n, s$, $r, d, a, t$ are used to represent the fractured wells, wastewater storages, reused water tanks in reuse units, rejected water tanks in disposal units, TMD system and time periods, respectively. Note that in the reuse units, the temporarily stored reused water is then sold in the market for drinking, urban or agricultural purposes. In the disposal units, the temporarily stored rejected water is then injected down the well and deep into the earth. More details about the TMD system are discussed in Section 3.1.2.

As Figure 3.1 shows, the wastewater coming out from the fractured wells can be stored in the storages near drilling sites, which will be transported to the TMD system to remove the TDS. All the collected wastewater is treated before being reused, or being directly dumped in disposal wells. Note that in this study, it is assumed that the reused water is sold in the market instead of being reintroduced as part of the fracturing fluid for drilling other shale wells. Based on the developed superstructure in Figure 3.1, a MINLP optimization model is presented for the optimal design and operation for wastewater management in the post-fracturing process, which is divided into three subsections. The first subsection focuses on the mass and contaminant balances and constraints; the second presents a detailed TMD model; the third gives all the associated costs and the overall objective function.

\subsubsection{Balance and Constraint}

\subsubsection{Mass and Contaminant Balance around Fractured Wells}

The wastewater recovered from hydraulic fracturing is transported to the wastewater storages. Eq. 1 states that the wastewater generated from fractured well $n$ in 
time period $t\left(F_{n, t}^{\text {well_out }}\right)$ is segregated and sent to each wastewater storage $s$ during the same time period $\left(f f_{n, s, t}^{\text {well_storage }}\right)$. Eq. 2 presents the corresponding TDS mass flow of the stream $\left(m m_{n, s, t}^{\text {well_storage }}\right)$ that comes out of well $n$ into storage $s$ in time period $t$, based on the segregated flowrate $\left(f f_{n, s, t}^{\text {well_storage }}\right)$ and TDS concentration $\left(C_{n, t}^{\text {wellout }}\right)$ of the wastewater leaving well $n$ in time period $t$.

$$
\begin{aligned}
& F_{n, t}^{\text {well_out }}=\sum_{s} f f_{n, s, t}^{\text {well_storage }}, \forall n, \forall t \\
& m m_{n, s, t}^{\text {well_storage }}=C_{n, t}^{\text {well_out }} f f_{n, s, t}^{\text {well_storage }}, \forall n, \forall s, \forall t
\end{aligned}
$$

\subsubsection{Mass and Contaminant Balance around Storage Units}

The outlet streams from different wells are blended in the inlet of storage $s$. Eqs.

3-4 describe the segregation of flowrate $\left(F_{s, t}^{\text {storage } i n}\right)$ and TDS mass flowrate $\left(M_{s, t}^{\text {storage }{ }_{-} i n}\right)$ of the mixture fluid entering storage $s$ in time period $t$, respectively.

$$
\begin{aligned}
& F_{s, t}^{\text {storage_in }}=\sum_{n} f f_{n, s, t}^{\text {well_storage }}, \forall s, \forall t \\
& M_{s, t}^{\text {storage_in }}=\sum_{n} m m_{n, s, t}^{\text {well_storage }}, \forall s, \forall t
\end{aligned}
$$

The TDS concentration of the mixture fluid $\left(C_{s, t}^{\text {storage } i n}\right)$ entering storage $s$ in time point $t$ is calculated in Eq. 5 .

$$
C_{s, t}^{\text {storage_in }}=\frac{M_{s, t}^{\text {storage } \_ \text {in }}}{F_{s, t}^{\text {storage_in }}}, \quad \forall S, \forall t
$$

Considering the tank as a continuous model, the mass balance equations for storage $s$ in time period $t$ are constructed in terms of the volume of stored wastewater $\left(V_{s, t}^{\text {storage }}\right)$, as stated in Eqs. 6-8. They represent that the volume change of the stored wastewater from 
time period $t-1$ is the difference between the amount of wastewater entering and leaving the storage in time period $t$ as follows:

$$
\begin{aligned}
& V_{s, t}^{\text {storage }}=V_{s}^{\text {storage_initial }}+H^{\text {time }}\left(F_{s, t}^{\text {storage_in }}-F_{s, t}^{\text {storage_out }}\right), \forall s, \forall t=1 \\
& V_{s, t}^{\text {storage }}=V_{s, t-1}^{\text {storage }}+H^{\text {time }}\left(F_{s, t}^{\text {storage } i n}-F_{s, t}^{\text {storage } e_{-} \text {out }}\right), \forall s, \forall t>1 \\
& V_{s, t}^{\text {storage }}=0, \forall s, \forall t=\text { end }
\end{aligned}
$$

Similarly, the contaminant balance equations in terms of the TDS concentration are constructed as shown in Eqs. 9-11.

$$
\begin{gathered}
C_{s, t}^{\text {storage_out }}=C_{s, t}^{\text {storage_in }}, \forall s, \forall t=1 \\
C_{s, t}^{\text {storage_out }} V_{s, t}^{\text {storage }}=C_{s, t-1}^{\text {storage_out }} V_{s, t-1}^{\text {storage }}+H^{\text {time }} C_{s, t}^{\text {storage_in }} F_{s, t}^{\text {storage }{ }_{-} i n}- \\
H^{\text {time }} C_{s, t}^{\text {storage_out }} F_{s, t}^{\text {storage_out }}, \forall s, \forall t>1 \\
0=C_{s, t-1}^{\text {storage_out }} V_{s, t-1}^{\text {storage }}+H^{\text {time }} C_{s, t}^{\text {storage_in }} F_{s, t}^{\text {storage } i n}- \\
H^{\text {time }} C_{s, t}^{\text {storage_out }} F_{s, t}^{\text {storage_out }}, \forall s, \forall t=\text { end }
\end{gathered}
$$

where $V_{s}^{\text {storage_initial }}$ is the initial wastewater volume in storage $s$ and $H^{\text {time }}$ is the operation time in each time period. Specifically, Eq. 8 implies that there should be no wastewater stored in any tanks at the end of wastewater management process $(t=e n d)$. $F_{s, t}^{\text {storage_out }}$ and $C_{s, t}^{\text {storage_out }}$ are the continuous variables specifying the flowrate and the TDS concentration of the wastewater stream leaving storage $s$ in time period $t$. This wastewater stream is separated and sent to the TMD system, as stated in Eq. 12. With the 
TDS concentration of the outlet stream $\left(C_{s, t}^{\text {storage_out }}\right)$ from storage $s$ in time period $t$, the corresponding mass flowrate of TDS ( $\left.\mathrm{mm}_{s, a, t}^{\text {storage_treatment }}\right)$ is presented in Eq. 13.

$$
\begin{aligned}
& F_{s, t}^{\text {storage_out }}=\sum_{a} f f_{s, a, t}^{\text {storage_treatment }}, \forall s, \forall t \\
& m m_{s, a, t}^{\text {storage_treatment }}=C_{s, t}^{\text {storage_out }} f f_{s, a, t}^{\text {storage_treatment }}, \forall s, \forall a, \forall t
\end{aligned}
$$

\subsubsection{Mass and Contaminant Balance around Treatment Unit}

The wastewater entering the TMD system is supplied by the outlet streams from storages, as stated in Eq. 14. Eqs. 15 and 16 indicate the total mass flowrate of TDS $\left(M_{a, t}^{\text {treatment_in }}\right)$ and the calculated TDS concentration $\left(C_{a, t}^{\text {treatment_in }}\right)$ respectively in the inlet stream to the TMD system $a$ in time period $t$.

$$
\begin{aligned}
& F_{a, t}^{\text {treatment_in }}=\sum_{s} f f_{s, a, t}^{\text {storage_treatment }}, \forall a, \forall t \\
& M_{a, t}^{\text {treatment_in }}=\sum_{s} m m_{s, a, t}^{\text {storage_treatment }}, \forall a, \forall t \\
& C_{a, t}^{\text {treatment_in }}=\frac{M_{a, t}^{\text {treatment_in }}}{F_{a, t}^{\text {treatment_in }}}, \forall a, \forall t
\end{aligned}
$$

After the treatment process, the treated water can be sent to the reuse or disposal units. Eq. 17 states that the flowrate of wastewater to be treated entering TMD system $a$ in time period $t\left(F_{a, t}^{\text {treatment_in }}\right)$ is the sum of the flowrate of the permeate streams that will be sent to reused water tanks $\left(f f_{a, r, t}^{\text {treatment_reuse }}\right)$ and the flowrate of concentrate streams that will be sent to rejected water tanks $\left(f f_{a, d, t}^{\text {treatment_disposal }}\right)$. Similarly, Eqs. 1820 describe the mass flowrate of TDS and the TDS concentration in the outlet streams of the TMD system $a$.

$$
F_{a, t}^{\text {treatment_in }}=\sum_{r} f f_{a, r, t}^{\text {treatment_reuse }}+\sum_{d} f f_{a, d, t}^{\text {treatment_disposal }}, \forall a, \forall t
$$




$$
\begin{aligned}
& M_{a, t}^{\text {treatment_in }}=\sum_{r} m m_{a, r, t}^{\text {treatment_reuse }}+\sum_{d} m m_{a, d, t}^{\text {treatment_disposal }}, \forall a, \forall t \\
& C_{a, r, t}^{\text {treatment_reuse }}=\frac{m m_{a, r, t}^{\text {treatment_reuse }}}{f f_{a, r, t}^{\text {treatment_reuse }}}, \forall a, \forall r, \forall t \\
& C_{a, d, t}^{\text {treatment_disposal }}=\frac{m m_{a, d, t}^{\text {treatment_disposal }}}{f f_{a, d, t}^{\text {treatment_disposal }}}, \forall a, \forall d, \forall t
\end{aligned}
$$

\subsubsection{Mass and Contaminant Balance around Reuse and Disposal Units}

The flowrate of the reused water entering reused water tank $r$ in time point $t$ $\left(F_{r, t}^{\text {reuse } \_i n}\right)$ is supplied by the permeate streams of the TMD system $\left(f f_{a, r, t}^{\text {treatment_reuse }}\right)$ while the flowrate of the rejected water entering rejected water tank $d$ in time period $t\left(F_{d, t}^{\text {disposal_in }}\right)$ is supplied by the concentrate streams of the TMD system $\left(f f_{a, d, t}^{\text {treatment_disposal }}\right)$. Assuming that the stream entering reused water tank $r$ in time period $t$ should be sold out at the end of the same time period, the amount of the water temporarily stored in reused water tank $r$ in time period $t\left(V_{r, t}^{r e u s e}\right)$ can be presented as stated in Eq. 23. Eq. 24 represents the same situation for the disposal units.

$$
\begin{aligned}
& F_{r, t}^{\text {reuse_in }}=\sum_{a} f f_{a, r, t}^{\text {treatment_reuse }}, \forall r, \forall t \\
& F_{d, t}^{\text {disposal_in }}=\sum_{a} f f_{a, d, t}^{\text {treatment_disposal }}, \forall d, \forall t \\
& V_{r, t}^{\text {reuse }}=H^{\text {time }} F_{r, t}^{\text {reuse_in }}, \forall r, \forall t \\
& V_{d, t}^{\text {disposal }}=H^{\text {time }} F_{d, t}^{\text {disposal_in }}, \forall d, \forall t
\end{aligned}
$$




\subsubsection{Design Constraint for Storage, Reuse and Disposal Units}

The optimal design is achieved by determining the optimum number as well as the optimum size of each unit. Except the TMD system, the constraints on the other units are formulated based on given maximum capacity. Binary variables are added to determine the number of established units. Eqs. 25 and 26 state that the capacity of storage $s$ should not exceed the maximum capacity and the corresponding binary variable indicates if this storage is required. Similarly, Eqs. 27 and 28 describe the constraints on the reuse units, and Eqs. 29 and 30 describe the constraints on the disposal units.

$$
\begin{aligned}
& V_{s, t}^{\text {storage }} \leq V_{s}^{\text {storage_capacity }}, \forall s, \forall t \\
& V_{s}^{\text {storage_capacity }} \leq V_{s}^{\text {storage_max }} y_{s}^{\text {storage }}, \forall s \\
& V_{r, t}^{\text {reuse }} \leq V_{r}^{\text {reuse_capacity }}, \forall r, \forall t \\
& V_{r}^{\text {reuse_capacity }} \leq V_{r}^{\text {reuse_max }} y_{r}^{\text {reuse }}, \forall r \\
& V_{d, t}^{\text {disposal }} \leq V_{d}^{\text {disposal_capacity }}, \forall d, \forall t \\
& V_{d}^{\text {disposal_capacity }} \leq V_{d}^{\text {disposal_max }} y_{d}^{\text {disposal }}, \forall d
\end{aligned}
$$

\subsubsection{Thermal Membrane Distillation (TMD) Model}

The detailed design model for TMD system is based on the work of Elsayed et al. ${ }^{30}$ A typical TMD module is presented in Figure 3.2. 


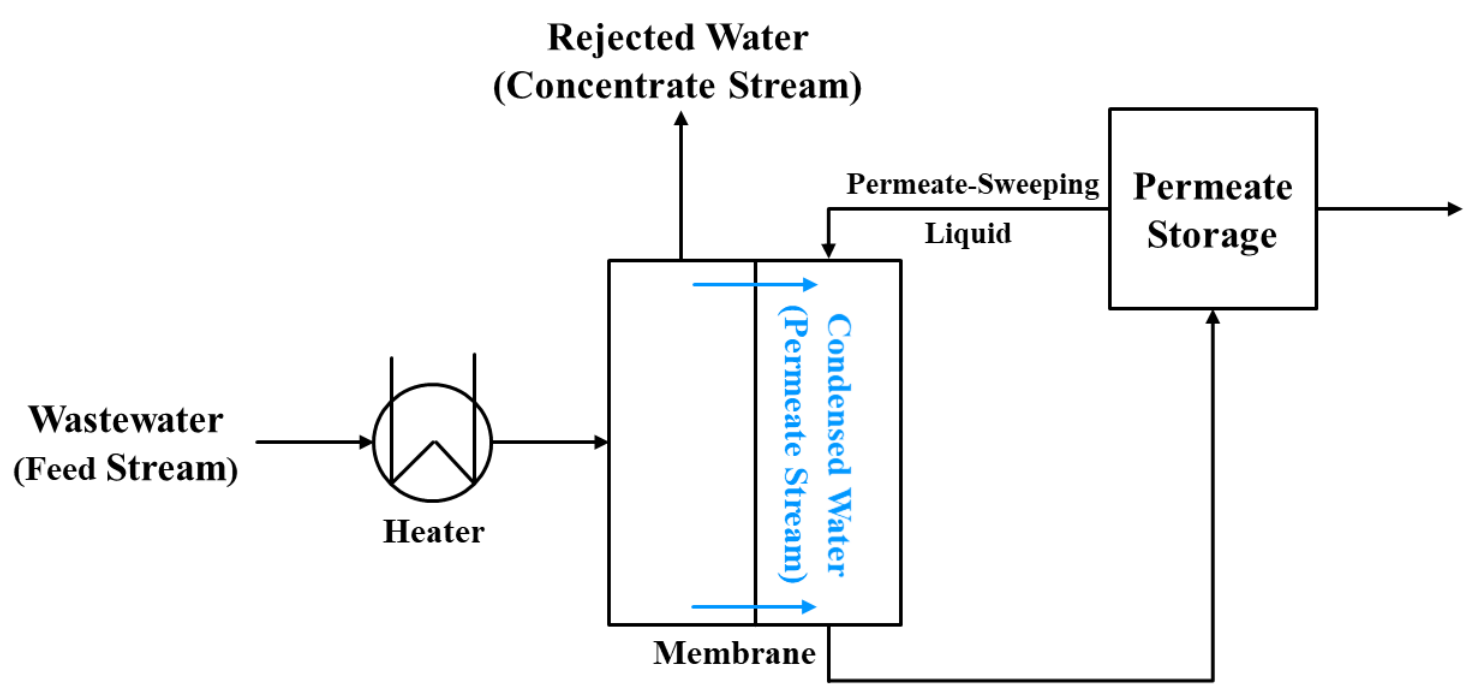

Figure 3.2 Schematic diagram for TMD system

In the TMD system, the wastewater in the inlet is preheated to achieve the vaporliquid equilibrium and thus remove organics and the other contaminants. The water vapor passes through the membrane and is condensed as a highly pure liquid on the permeate side. The driving force for water flux $\left(J_{a, t}\right)$ across the membrane in TMD system $a$ in time period $t$ is the difference in chemical potential which is dependent on the vapor pressure difference between the feed and the permeate sides as stated in Eq. 31 .

$$
J_{a, t}=B_{w}\left(P_{\text {feed }}^{v} \gamma_{w, \text { feed }, a, t} x_{w, f e e d, a, t}-P_{\text {perm }}^{v}\right), \quad \forall a, \forall t
$$

where $\gamma_{w, \text { feed,a,t }}$ and $x_{w, \text { feed,a,t }}$ are the activity coefficient and the mole fraction of the wastewater entering the TMD system $a$ in time period $t, B_{w}$ is the membrane permeability, $P_{\text {feed }}^{v}$ is the water vapor pressure of feed stream and $P_{\text {perm }}^{v}$ is the water vapor pressure of the permeate stream. Eqs. 32-33 describe the water vapor pressures via 
Antoine equation, and Eq. 34 is proposed to determine the membrane permeability $\left(B_{w}\right)$ of the TMD system. ${ }^{31}$

$$
\begin{aligned}
& P_{\text {feed }}^{v}=\exp \left(23.1964-\frac{3816.44}{T_{m, \text { feed }}-46.13}\right) \\
& P_{\text {perm }}^{v}=\exp \left(23.1964-\frac{3816.44}{T_{m, \text { perm }}-46.13}\right) \\
& B_{w}=B_{w b} T_{m}{ }^{1.334} \\
& T_{m}=\frac{T_{b, \text { feed }}+T_{b, \text { perm }}}{2}=\frac{T_{m, \text { feed }}+T_{m, \text { perm }}}{2}
\end{aligned}
$$

where $T_{m \text {,feed }}$ and $T_{m \text {,perm }}$ are the temperatures of the feed stream and the permeate stream on the membrane while $T_{b, \text { feed }}$ and $T_{b, p e r m}$ are the bulk temperatures of the feed stream and the permeate stream, $B_{w b}$ is the temperature-independent base value for permeability which is determined based on experimental data. Thus, the average membrane temperature $T_{m}$ is defined in Eq. 35. Since the differences between $T_{m \text {,feed }}$ and $T_{b, f e e d}$, and $T_{m, p e r m}$ and $T_{b, p e r m}$ are almost the same, $T_{m}$ can be calculated using the membrane temperature. ${ }^{30}$ In this study, we assume that the feed stream is pre-heated to $363 \mathrm{~K}$ and the temperature difference is kept constant as $25 \mathrm{~K}$, thus $P_{\text {feed }}^{v}, P_{\text {perm }}^{v}$ and $B_{w}$ are fixed parameters.

Assuming the primary solute in the wastewater is $\mathrm{NaCl}$, with the TDS concentration of the stream entering the TMD system $a$ in time period $t\left(C_{a, t}^{\text {treatment_in }}\right)$, the molar concentration of water $\left(x_{w, \text { feed,a,t }}\right)$ and the activity coefficient of water $\left(\gamma_{w, f e e d, a, t}\right)$ entering the TMD system $a$ in time period $t$ are calculated using Eqs. 36$38 .^{32}$ 


$$
\begin{aligned}
& x_{N a C l, f e e d, a, t}=\frac{\frac{c_{a, t}^{\text {treatment_in }}}{58}}{\frac{c_{a, t}^{\text {treatment_in }}}{58}+\frac{1-C_{a, t}^{\text {treatment_in }}+i n}{18}}, \forall a, \forall t \\
& x_{w, f e e d, a, t}=1-x_{N a C l, f e e d, a, t, \quad \forall a, \forall t} \\
& \gamma_{w, f e e d, a, t}=1-0.5 x_{N a C l, f e e d, a, t}-10 x_{N a C l, f e e d, a, t}^{2}, \quad \forall a, \forall t
\end{aligned}
$$

Thus, the decision variable, which is the area of the membrane $\left(A_{m, a}\right)$ required for the TMD system $a$, is determined using Eqs. 39-40. Then, the corresponding annual operation cost ( $\left.\operatorname{Cost}_{a, t}^{\text {treatment }}\right)$ and the annual capital cost ( $\left.\operatorname{CapCOST} T_{a, t}^{\text {treatment }}\right)$ for the TMD system $a$ in time period $t$ are given as Eqs. $41-42 .{ }^{30}$ The water recovery $\left(\zeta_{a, t}\right)$, which is defined as the flowrate ratio of the permeate stream to the feed stream, and the recycle ratio $\left(v_{a, t}\right)$, which is defined as the flowrate ratio of the concentrate stream to the feed stream, are calculated using Eqs. 43-44. Note that the associated costs of the TMD system are dependent on $A_{m, a}$ and $F_{a, t}^{\text {treatment_in }}$. Since there are no specific constraints on these key variables, it is assumed that there is only one TMD system in this network, which is capable to deal with all the generated wastewater.

$$
\begin{aligned}
& A_{m, a, t}=\frac{\sum_{r} f f_{a, r, t}^{\text {treatment_reuse }}}{J_{a, t}}, \forall a, \forall t \\
& A_{m, a} \geq A_{m, a, t}, \quad \forall a \\
& \text { Cost }_{a, t}^{\text {treatment }}=\left[1411+43\left(1-\zeta_{a, t}\right)+1613\left(1+v_{a, t}\right)\right] F_{a, t}^{\text {treatment_in }}, \forall a, \forall t \\
& \text { CapCOST }_{a, t}^{\text {treatment }}=58.5 A_{m, a}+1115 F_{a, t}^{\text {treatment_in }}, \forall a, \forall t \\
& \zeta_{a, t}=\frac{\sum_{r} f f_{a, r, t}^{\text {treatment_reuse }}}{F_{a, t}^{\text {treatment_in }}}, \forall a, \forall t
\end{aligned}
$$




$$
v_{a, t}=\frac{\sum_{d} f f_{a, d, t}^{\text {treatment_disposal }}}{F_{a, t}^{\text {treatment_in }}}, \forall a, \forall t
$$

As mentioned, the permeate streams are highly pure liquid, thus the complete rejection is assumed. To avoid the build-up of contaminants and precipitation in the TMD system, the TDS weight fraction in the concentrate streams should not exceed 0.35 . The constraints on the TDS weight fraction are presented in Eqs. $45-46 .^{30}$

$$
\begin{aligned}
& C_{a, r, t}^{\text {treatment_reuse }}=0, \forall a, \forall r, \forall t \\
& C_{a, d, t}^{\text {treatment_disposal }} \leq 0.35, \forall a, \forall d, \forall t
\end{aligned}
$$

where if $C_{a, d, t}^{\text {treatment_disposal }}=0.35, \zeta_{a, t}$ should reach its maximum value. Hence, an implicit constraint is described in Eq. $47 .^{30}$

$$
\zeta_{a, t} \leq 1-\frac{C_{a, t}^{\text {treatment_in }}}{0.35}, \forall a, \forall t
$$

REMARK 1. The dynamics of the membrane separation processes may become significant if there is the fouling effect of the membrane. ${ }^{33}$ For example, in Reverse Osmosis (RO), the permeability may change dynamically due to the fouling effect, as a result of low rejection rate. However, TMD has a high rejection factor, which is validated through the principle of vapor-liquid equilibrium, and its membrane pore size is relatively larger than other membrane separation processes, such as RO. Therefore, TMD has very low fouling and it is not necessary to consider the membrane's dynamics in this work. ${ }^{32}$

\subsubsection{Objective Function}

The objective of the developed MINLP optimization model is to minimize the total annual cost, accounting for the operation cost (associated with transportation, TMD 
system, and disposal units), the capital cost (associated with storage units, TMD system, reuse units and disposal units), and the revenue (associated with reuse units).

\subsubsection{Treatment Cost}

As discussed in Section 3.1.2, the total operating cost for the TMD system is stated in Eq. 48. Note that $T$ is the number of the time periods considered.

$$
\operatorname{Cost}^{\text {treatment }}=\frac{\sum_{a, t}\left[1411+43\left(1-\zeta_{a, t}\right)+1613\left(1+v_{a, t}\right)\right] F_{a, t}^{\text {treatment_in }}}{T}
$$

\subsubsection{Disposal Cost}

Given the unit operating cost for a disposal unit (UOC disposal $)$, the total disposal cost is presented in Eq. 49.

$$
\operatorname{Cost}^{\text {disposal }}=\sum_{d, t} U O C^{\text {disposal }} F_{d, t}^{\text {disposal_in }}
$$

\subsubsection{Transportation Cost}

Given the unit transportation costs (UTC) between units, the associated transportation costs are stated in Eqs. 50-53 and the total transportation cost is obtained as Eq. 54.

$$
\begin{aligned}
& \text { TransCost }{ }^{\text {well_storage }}=H^{\text {time }} \sum_{n, s, t} U T C^{\text {well_storage }} f f_{n, s, t}^{\text {well_storage }} \\
& \text { TransCost }{ }^{\text {storage_treatment }}= \\
& H^{\text {time }} \sum_{s, a, t} U T C^{\text {storage_treatment }} f f_{s, a, t}^{\text {storage_treatment }} \\
& \text { TransCost } t^{\text {treatment_reuse }}=H^{\text {time }} \sum_{a, r, t} U T C^{\text {treatment_reuse }} f f_{a, r, t}^{\text {treatment_reuse }}
\end{aligned}
$$


TransCost ${ }^{\text {treatment_disposal }}=$

$H^{\text {time }} \sum_{a, d, t} U T C^{\text {treatment_disposal }} f f_{a, \mathrm{~d}, t}^{\text {treatment_disposal }}$

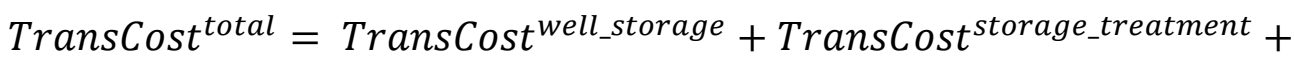

TransCost ${ }_{\text {treatment_reuse }}+$ TransCost ${ }_{\text {treatment_disposal }}$

\subsubsection{Capital Cost}

As discussed in Section 3.1.2, the total capital cost for the TMD system is stated below.

$$
\text { CapCost } \text { treatment }^{\text {reatme }} \sum_{a} 58.5 A_{m, a}+\frac{\sum_{a, t} 1115 F_{a, t}^{\text {treatment }} \text { in }}{T}
$$

The capital costs for storage, reuse, and disposal units are given in Eqs. 56-58, which are taken from Lira-Barragan et al. ${ }^{5}$

$$
\begin{aligned}
& \text { CapCost }{ }^{\text {storage }}=K \sum_{s}\left[F C^{\text {storage }} y_{s}^{\text {storage }}+\left(V C^{\text {storage }} V_{s}^{\text {storage_capacity }}\right)\right] \\
& \text { CapCost }{ }^{\text {reuse }}=K \sum_{r}\left[F C^{\text {reuse }} y_{r}^{\text {reuse }}+\left(V C^{\text {reuse }} V_{r}^{\text {reuse_capacity }}\right)\right] \\
& \text { CapCost }^{\text {disposal }}=K \sum_{d}\left[F C^{\text {disposal }} y_{d}^{\text {disposal }}+\left(V C^{\text {disposal }} V_{d}^{\text {disposal_capacity }}\right)\right]
\end{aligned}
$$

where $K$ is a factor used to annualize the inversion; $F C^{\text {storage }}, F C^{\text {reuse }}, F C^{\text {disposal }}$ are fixed charges included in the capital cost functions for storage units, reuse units and disposal units, respectively; $V C^{\text {storage }}, V C^{\text {reuse }}, V C^{\text {disposal }}$ are the corresponding variable charges. 


\subsubsection{Profit}

Given the unit profit from reusing water $\left(U P^{\text {reuse }}\right)$, the total Profit is presented in Eq. 59.

$$
\text { Profit }{ }^{\text {reuse }}=H^{\text {time }} \sum_{r, t} U P^{\text {reuse }} F_{r, t}^{\text {reuse_in }}
$$

\subsubsection{Total Annual Cost (TAC)}

Thus, the total annual cost associated with the wastewater management can be presented as stated in Eq. 60:

$$
\begin{aligned}
& \quad \text { TAC }=\left(\text { Cost }^{\text {treatment }}+\text { Cost }^{\text {disposal }}+\text { TransCost }^{\text {total }}\right)+ \\
& \left(\text { CapCost }^{\text {treatment }}+\text { CapCost }^{\text {storage }}+\text { CapCost }^{\text {reuse }}+\text { CapCost }^{\text {disposal }}\right)- \\
& \text { Profit }
\end{aligned}
$$

\subsection{Model Predictive Control for Hydraulic Fracturing}

In this section, the proposed novel MPC system is presented, as shown in Figure

\section{3.}

\section{MPC System}

\section{(Maximized Net Profit from Shale Gas Development)}
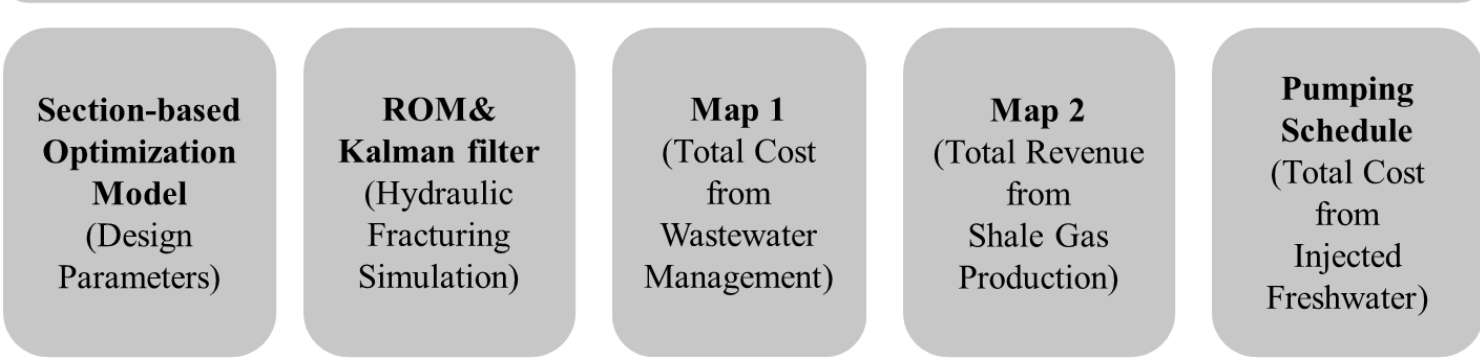

Figure 3.3 Schematic diagram for MPC system 
To combine the economic factors (i.e., revenue from shale gas production, cost from wastewater management and cost from freshwater) with the simulation of hydraulic fracturing process and design the integrated MPC system, a mapping-based technique is proposed. With the overall objective to maximize the net profit from the shale gas development, two maps are generated. By applying the optimization model developed in Section 3.1 for wastewater management, the minimized total cost is obtained based on given flowrate and TDS concentration profiles of wastewater. Thus, with the dynamic input-output model which correlates the pumping schedule and recovered wastewater, the first map is generated describing the total annual cost associated with the wastewater management strategy. Then, applying multiple random pumping schedules to the developed reduced-order model and Kalman filter, their corresponding final fracture geometries are obtained. Thus, based on the obtained fracture geometries and market price of shale gas, the second map is generated using CMG software, which describes the total revenue associated with the shale gas production. Along with the freshwater cost which is obtained based on the pumping schedule, the MPC system is constructed. Particularly, the section-based optimization model is included to provide the necessary design parameters used in the MPC formulation.

\subsubsection{Section-based Optimization Model}

The section-based optimization model is adopted from Liu and Valko. ${ }^{34}$ It is used to determine the optimum number of wells $\left(n_{c}\right)$, number of fractures per well $\left(n_{r}\right)$ and propped fracture half-length $\left(x_{f}\right)$, which maximize the dimensionless productivity index $(P I)$ for a given amount of injected proppant $\left(M_{\text {prop }}\right) \cdot{ }^{34}$ 
Defining that the large square drainage area for multi-stage fractured horizontal wells is the section and drainage area for a single fracture is the subsection, the relationship between the section area $\left(A_{\text {section }}\right)$ and the subsection area $\left(A_{\text {subsection }}\right)$ is presented in Eq. 61.

$$
A_{\text {section }}=A_{\text {subsection }} n_{c} n_{r}
$$

Assuming that the created fractures will be of infinite conductivity and the injected amount of proppant is enough to ensure the enhanced permeability over the entire section, the overall dimensionless productivity of a section $\left(J_{D}\right)$ is shown in Eqs. 62-64.

$$
\begin{aligned}
& J_{D}=n_{f} J_{D, f}\left(A_{r}, I_{x}\right) \\
& n_{f}=n_{c} n_{r} \\
& A_{r}=\frac{n_{r}}{n_{c}}, I_{x}=\frac{l_{f}}{n_{r} \sqrt{A_{\text {section }}}}, l_{f}=\frac{M_{\text {prop }}}{\rho_{p} W_{\text {opt }} H_{r}}
\end{aligned}
$$

where $n_{f}$ is the total number of fractures in the section, $J_{D, f}$ is the dimensionless productivity index $(\mathrm{PI})$ for a fracture, which is a function of aspect ratio $\left(A_{r}\right)$ and penetration ratio $\left(I_{x}\right) ; l_{f}$ is the total fracture length, $M_{\text {prop }}$ is the total amount of injected proppant, $\rho_{p}$ is the proppant particle density, $W_{o p t}$ is the minimum required average propped fracture width, and $H_{r}$ is the reservoir thickness. Given that the values of $M_{\text {prop }}$, $W_{o p t}, H_{r}$ and $A_{\text {section }}$ are available, the three decision variables mentioned above $\left(n_{c}, n_{r}, x_{f}\right)$ can be determined.

Assuming the proppant bank will cover the optimum propped fracture half-length $\left(x_{f}\right)$ with the equilibrium proppant bank height $\left(h_{e q}\right)$, the desired average fracture width 
over the optimum propped fracture half-length $\left(W_{\text {avg,target }}\right)$ is calculated as stated in Eq. 65.

$$
W_{\text {avg,target }}=\frac{M_{\text {prop }, f}}{2 \rho_{p} h_{e q} x_{f}(1-\phi)}
$$

where $M_{\text {prop,f }}$ is the given injected proppant amount for one fracture, $\phi$ is the proppant bank porosity. When pumping is stop, the fracturing fluid will leak off and the proppant will be trapped by fractured wells; this phenomenon is called fracture closure. Note that $W_{\text {opt }}$ is the average fracture width at the end of fracture closure while $W_{\text {avg,target }}$ is the average fracture width at the end of pumping. One assumption is that over the course of fracture closure process, the average fracture width will decrease from $W_{\text {avg,target }}$ to $W_{\text {opt }}$.

\subsubsection{Reduced-order Model and Kalman filter}

By applying the proppant bank formation mechanism, a nonlinear high-fidelity model for hydraulic fracturing process is developed by Siddhamshetty et al. ${ }^{23}$ With the input/output simulation data generated by the high-fidelity model where the input is the pumping schedule and the output is the final fracture geometry, a linear time-invariant state-space model of the hydraulic fracturing process is developed using the multivariable output error state-space (MOESP) algorithm . The model formulation is shown in Eqs. 6667.

$$
\begin{aligned}
& x\left(t_{k+1}\right)=A x\left(t_{k}\right)+B u\left(t_{k}\right) \\
& y\left(t_{k}\right)=C x\left(t_{k}\right)
\end{aligned}
$$


where $u\left(t_{k}\right)$ is the input, $x\left(t_{k}\right)$ is the state, and $y\left(t_{k}\right)$ is the output at time point $t_{k}$. The parameters $(A, B, C)$ are determined by the MOESP algorithm. Specifically, the input includes the flowrate $Q_{0}\left(t_{k}\right)$ and the proppant concentration $C_{0}\left(t_{k}\right)$ of the injected fracturing fluid at the wellbore. The output includes the average fracture width over the optimum fracture half-length $W_{a v g, x_{f}}\left(t_{k}\right)$, the fracture width at the wellbore $W_{0}\left(t_{k}\right)$, and the fracture length $L\left(t_{k}\right)$. Note that among the three output variables, the real-time measurements of $W_{0}\left(t_{k}\right)$ and $L\left(t_{k}\right)$ are assumed to be available during the operation of hydraulic fracturing.

To obtain the unmeasurable output variable, $W_{a v g, x_{f}}\left(t_{k}\right)$, a Kalman filter is developed. Eqs. $68-70$ state that the Kalman filter is designed based on the obtained reduced-order model and the available measurements as follows:

$$
\begin{aligned}
& \hat{x}\left(t_{k+1}\right)=\mathrm{A} \hat{x}\left(t_{k}\right)+B u\left(t_{k}\right)+M\left(t_{k}\right)\left[y_{m}\left(t_{k}\right)-\hat{y}\left(t_{k}\right)\right] \\
& M\left(t_{k}\right)=P\left(t_{k}\right) H^{T}\left[R\left(t_{k}\right)+C P\left(t_{k}\right) C^{T}\right]^{-1} \\
& P\left(t_{k+1}\right)=\left[I-M\left(t_{k}\right) C\right] P\left(t_{k}\right)
\end{aligned}
$$

where $u\left(t_{k}\right)$ is the input, $\hat{x}\left(t_{k}\right)$ and $\hat{y}\left(t_{k}\right)$ are the estimates of the state and output variables, $M\left(t_{k}\right)$ is the Kalman filter gain, and $P\left(t_{k}\right)$ is the covariance of the state estimation error. The Kalman filter allows the state estimates to be updated iteratively based on the available real-time measurements, which makes the state estimation more accurate. 


\subsubsection{Map 1}

As mentioned, a dynamic input-output model for flowback water is developed based on field data to describe the relationship between the input (i.e., pumping schedules) and the output (i.e., flowrate and TDS concentration profiles of wastewater).

Based on the operational definition, flowback water is the wastewater which returns to the surface within the first few weeks after hydraulic fracturing is completed, and produced water is the wastewater generated in the production stage along with shale gas. Flowback water is characterized by a high flowrate and a low TDS concentration. Produced water, by contrast, returns to the surface with a high TDS concentration due to bringing the components associated with the formation and the entrapped fluid in the pore spaces. After hydraulic fracturing is completed, the pressure in the formation is gradually released along with time and injected fracturing fluid picks up inorganic constituents when residing downhole. Thus, the trend of continuously increasing TDS concentration and decreasing flowrate is predominant for wastewater. In this regard, we assume that the flowrate and TDS concentration can be represented by time-varying continuous variables. Since the characteristics of the wastewater would change little in the last few years as reported, natural logarithm equations are assumed to develop the input-output model by a regression technique. ${ }^{35}$ Thus, the flowrate profile and the TDS concentration profile are formulated as stated in Eqs. 71 and 72, respectively.

$$
\begin{aligned}
& F_{n, t}^{\text {well_out }}=Q_{n}^{\text {injected }}(\operatorname{aln}(t)+b), \quad \forall n \forall t \\
& C_{n, t}^{\text {well_out }}=c \ln (t)+d, \quad \forall n \forall t
\end{aligned}
$$


where $a, b, c, d$ are parameters determined by the regression technique, and $Q_{n}^{\text {injected }}$ is the total volume of injected fluid for fractured well $n$. Note that the flowrate profile changes with the volume of injected fluid, while the TDS concentration profile remains the same since it is only a function of time.

By injecting fracturing fluids with different volumes, a variety of flowrate profiles can be generated. They are then used with the TDS concentration profile as the inputs to the wastewater management optimization model to compute the corresponding minimized total annual costs. Thus, a map is constructed that shows the total annual cost $(T A C)$ from the wastewater management process as a function of the volume of injected fracturing fluid for one fractured well. Note that to develop the map, it is assumed that all the wells are identical, and thus, the volume of injected fluid for each well can be denoted as $Q^{\text {injected }}$

$$
T A C=g\left(Q^{\text {injected }}\right)
$$

It is noted that $Q^{\text {injected }}$ can be calculated based on the pumping schedule, which provides the flowrate $\left(Q_{0}\left(t_{k}\right)\right)$ and the proppant concentration $\left(C_{0}\left(t_{k}\right)\right)$ of the injected fracturing fluid. Assuming that $Q^{\text {injected }}$, refers to the volume of the injected pure water (i.e., injected freshwater) for one fractured well, it can be calculated using Eq. 74 as follows:

$$
Q^{\text {injected }}=\Delta\left(\sum_{k} 2 Q_{0}\left(t_{k}\right)\left(1-C_{0}\left(t_{k}\right)\right)\right) n_{r}
$$

where $\Delta$ is the sampling time in the simulation work, $n_{r}$ is the number of fractures per well determined by the section-based optimization model. Note that the amount of injected 
freshwater for each well is identical and should be the sum of the freshwater required for all the fractures inside.

REMARK 2. In this work, the flowrate and TDS concentration profiles are generated based on the ROM and Kalman filter discussed in Section 3.2.2. In comparison to taking the sampled data from some reports directly, the main novelty here is to find the required fracturing fluid volume to create the desired fracture geometry (i.e., fracture length, height and average width) which will affect the total shale gas production rate. Then, with the developed dynamic input-output model, the corresponding flowrate and TDS concentration profiles can be determined with the obtained injected fracturing fluid volume.

\subsubsection{Map 2}

As mentioned, the reservoir simulation software, $\mathrm{CMG}$, is used to generate the shale gas production profile based on the final fracture geometry at the end of fracture closure.

With the component properties and the rock-fluid properties of a shale reservoir as well as the operation conditions, the numerical reservoir simulator of CMG is applied to model hydraulic fractures using one of its packages called GEM. Specifically, we focus on the modeling of one-wing fracture due to the symmetric nature of the bi-wing structure. Using the propped fracture geometry as the input, the shale gas production profile can be obtained. The total revenue from shale gas production (TRSG) for the shale reservoir can be calculated using Eq. $75 .^{36}$

$$
T R S G=\int_{0}^{t_{b}}\left(\overline{q_{0}} r_{0}(1+I)^{-c t}\right) n_{c} d t
$$


where $\overline{q_{0}}$ is the shale gas production rate for one fractured well, $t_{b}$ is the gas breakthrough time, $I$ is the money discount rate, $r_{0}$ is the market price of shale gas, $c$ is the time constant and $n_{c}$ is the number of the wells determined by section-based optimization model. In this work, the parameters $I$ and $c$ are taken to be 0.1 and $\frac{1}{365}(1 /$ day $)$, respectively.

The input to CMG-GEM is the propped fracture geometry (i.e., the fracture geometry at the end of fracture closure), which includes the average propped fracture width $\left(W_{o p t}\right)$, propped fracture half-length $\left(L_{f}\right)$ and propped fracture height $\left(H_{r}\right)$. Here, the propped fracture half-length for each fracture is calculated using Eq. 76 and $M_{\text {prop,frac }}$ is the final amount of the injected proppant for one fracture.

$$
L_{f}=\frac{M_{\text {prop }, \text { frac }}}{\rho_{p} h_{e q} W_{a v g, x_{f}}(1-\phi)}
$$

A set of different propped fracture geometries is used as the input to CMG-GEM to generate the corresponding shale gas production profiles with the associated revenue. Thus, a second map is developed, as presented in Eq. 77, where the total revenue (TRSG) obtained by selling shale gas produced is a function of the propped fracture geometries $\left(W_{o p t}, L_{f}, H_{r}\right)$.

$$
T R S G=h\left(W_{o p t}, L_{f}, H_{r}\right)=h\left(L_{f}\right)
$$

In this study, we assumed that fracture propagation is confined within a layer so the propped fracture height does not change much, and the average propped fracture width is taken to be three times the diameter of proppant particles, which is used as the minimum required propped fracture width. Thus, the revenue only changes with the propped fracture 
half-length. Note that since all the wells are assumed to be identical, the fracture geometries and the corresponding shale gas production rate for each well are the same.

\subsubsection{MPC Formulation}

Since the volume of the injected freshwater for one well is determined based on the pumping schedule as stated in Eq. 74, the total freshwater cost $(T F C)$ for the shale reservoir is obtained in Eq. 83 with given unit cost for freshwater $\left(U C^{\text {fresh }}\right)$. Finally, the novel MPC system is formulated as in Eq. 78 to maximize the net profit associated with the shale reservoir development as follows:

$$
\begin{aligned}
& \max _{C_{\text {stage }, k, \ldots, C_{\text {stage }, 9}} \text { TRSG }-T A C-T F C} \\
& \text { s.t. } \quad \text { Kalman filter }, \ldots, Q_{\text {stage }, 9} \\
& \widehat{W}_{0}\left(t_{k}\right)=W_{0}\left(t_{k}\right), \hat{L}\left(t_{k}\right)=L\left(t_{k}\right) \\
& T R S G=h\left(L_{f}\right) \\
& T A C=g\left(Q^{\text {injected }}\right) \\
& T F C=U C^{\text {fresh }}\left(Q^{\text {injected }} n_{c}\right) \\
& L_{f}=\frac{M_{\text {prop }, \text { frac }}}{\rho_{p} h_{\text {eq }} \widehat{W}_{\text {avg }, x_{f}}(1-\phi)} \\
& Q^{\text {injected }}=\Delta\left(\sum_{k} 2 Q_{\text {stage }, k}\left(1-C_{\text {stage }, k}\right)\right) n_{r} \\
& M_{\text {prop }, \text { frac }}=\Delta\left(\sum_{k=1}^{9} 2 Q_{\text {stage }, k} C_{\text {stage }, k}\right) \\
& C_{\text {stage }, k-1+m} \leq C_{\text {stage }, k+m} \leq C_{\text {max }} \\
& Q_{\text {min }} \leq Q_{\text {stage }, k+m} \leq Q_{\text {max }} \\
& M_{\text {prop }, \text { frac }} \leq M_{\text {prop }, f}
\end{aligned}
$$




$$
\begin{aligned}
& \widehat{W}_{\text {avg, } x_{f}}=W_{\text {avg,target }}=\frac{M_{\text {prop }, f}}{2 \rho_{p} h_{e q} x_{f}(1-\phi)} \\
& m=1, \ldots 9-k
\end{aligned}
$$

where Eq. 79 represents the Kalman filter developed in Section 3.2.2. Eq. 80 states that the Kalman filter is initiated by utilizing the real-time measurement of the fracture width at the wellbore $\left(W_{0}\left(t_{k}\right)\right)$ and fracture length $\left(L\left(t_{k}\right)\right)$ at each sampling time $t_{k}$, as initial conditions. Eqs. 81 and 82 are the two maps generated to calculate the total revenue from shale gas production, and the total annual cost from wastewater management. The two maps are based on the propped fracture half-length $\left(L_{f}\right)$ and the volume of the injected freshwater $\left(Q^{\text {injected }}\right)$ for one fractured well, which are calculated using Eqs. 84 and 85. It is noted that the number of fractured wells in the wastewater management optimization model is $N=n_{c}$. With the given unit cost $\left(U C^{\text {fresh }}\right)$ for the freshwater required to be injected, the total cost for the freshwater $(T F C)$ is calculated using Eq. 83. With $C_{\text {stage }, k}$ and $Q_{\text {stage,k }}$ representing the inlet proppant concentration and the inlet flowrate of fracturing fluid at the $k^{\text {th }}$ pumping stage, the volume of injected pure water for one fractured well ( $\left.Q^{\text {injected }}\right)$ and the amount of proppant injected to one well $\left(M_{\text {prop,frac }}\right)$ during hydraulic fracturing are calculated using Eqs. 85 and 86 . Eqs. 87 and 88 are the constraints imposed on the flowrate and proppant concentration; in particular, the proppant concentration increases with time but it should not exceed the maximum. Since the average propped fracture width $\left(W_{o p t}\right)$ is fixed, with the assumption mentioned in Section 3.2.1, the estimated average fracture width at the end of pumping $\left(\widehat{W}_{\text {avg, } x_{f}}\right)$ should be equal to the desired value ( $\left.W_{\text {avg,target }}\right)$ and calculated as stated in Eq. $90 . M_{\text {prop,f }}$ is the 
given amount of injected proppant for one fracture to make sure that the average fracture width will decrease to three times the diameter of proppant particles at the end of fracture closure. Eq. 89 implies that the final injected proppant amount $\left(M_{\text {prop,frac }}\right)$ could be less than the given value, $M_{\text {prop,f }}$, due to a possible decrease in the volume of injected fracturing fluid.

In this work, since the inputs of the wastewater management optimization model are the flowrate and TDS concentration profiles, which are determined by the pumping schedule, hydraulic fracturing will directly affect the wastewater management. Although the cost associated with the wastewater management is always minimized and not directly sent back to the hydraulic fracturing model, since it is included in the MPC to maximize the net profit, wastewater management will also affect the hydraulic fracturing. Thus, the hydraulic fracturing process and the wastewater management are simultaneously optimized to reach the maximized net profit.

REMARK 3. In this MPC, the linear ROM is used to approximate the nonlinear high-fidelity hydraulic fracturing model, and the Kalman filter is developed to estimate the unmeasurable average fracture width and initial states of the system, which will be used in the MPC to predict future state trajectories. When developing the ROM, the trained input profiles are selected within the range which can cover the entire range of operating conditions that are generally being considered in the field (i.e., the upper bound and lower bound on the flowrate and proppant concentration of injected fracturing fluid). Since these ranges are also included in the MPC formulation as the important constraints (i.e., Eqs. 87 and 88), the obtained ROM is always valid for this simulation work. 
REMARK 4. In this work, the focus is to investigate the trade-off between the hydraulic fracturing and water management. Since the objective function of MPC is directly related to the economic performance for shale gas development and the regulation of fracture geometry to a desired value is included as one constraint (i.e., Eq. 90), this MPC can also be described as economic model predictive control (EMPC) which refers to a framework that integrates economic process optimization and process control. 


\section{CASE STUDY AND ANALYSIS*}

In order to demonstrate the performance of the proposed control framework, an example representing a typical hydraulic fracturing process in the horizontal wells taken from Siddhamshetty et al. is considered. ${ }^{23}$ During the operation of hydraulic fracturing, the total amount of proppant used for the large square drainage area of $A_{\text {section }}=2.59 \times$ $10^{6} \mathrm{~m}^{2}$ is $M_{\text {prop }}=2.409 \times 10^{7} \mathrm{~kg}$, and the desired average fracture width at the end of pumping is $W_{\text {avg,target }}=5.37 \mathrm{~mm}$. It is noted that in this study, we mainly focus on the net profit within the first production year.

As discussed in Section 3.2.1, through the section-based optimization model, the fixed amount of proppant is converted to the total fracture length, which has to be satisfied to maximize the dimensionless productivity index $(P I)$. Specifically, when the average propped width of $W_{o p t}=2.9 \mathrm{~mm}$ and the reservoir thickness of $H_{r}=60 \mathrm{~m}$ are considered, the corresponding optimum number of wells $\left(n_{c}\right)$, number of fractures per well $\left(n_{r}\right)$ and propped fracture half-length $\left(x_{f}\right)$ are found to be 6,55 and $120 \mathrm{~m}$, respectively. These are used as the key parameters in the subsequent optimization problem for wastewater management and the control system for hydraulic fracturing. Details of the solution are provided in Appendix A.

\footnotetext{
*Reprinted with permission from "Economic model-based controller design framework for hydraulic fracturing to optimize shale gas production and water usage" by Cao, K.; Siddhamshetty, P.; Ahn, Y.; Mukherjee, R. and Kwon, J. S. 2019. Ind. Eng. Chem. Res., 2019. Copyright 2019 American Chemical Society.
} 


\subsection{Optimization of Wastewater Management}

\subsubsection{Dynamic Input-Output Model}

To obtain the flowrate profile and TDS concentration profile of the wastewater recovered within the first year, a dynamic input-output model is developed based on the field data taken from the information provided by Hayes et al. ${ }^{35}$ The field data are provided in Table B.1 and B.2 in Appendix B. In the report, the sampled data are obtained from 19 locations within the Marcellus Shale Region, presenting the volume of injected fracturing fluid, and the cumulative volume of the flowback water recovered on day 1, 5, 14 and 90 (since the completion of hydraulic fracturing) as well as the corresponding TDS concentration.

To effectively develop an input-output model, some assumptions are made. First of all, the fact that the regional characteristics of flowback water can vary significantly from one place to another is neglected. Second, only the TDS coming from the shale formation after well completion is considered. Thus, the TDS concentration on day 0 is assumed to be negligible. Third, the injected fluid is assumed to be pure water. Focusing on the horizontal drilling data from the report ${ }^{35}$, the sampled data from the location $\mathrm{C}, \mathrm{D}$, E, F, G, K, M, O is used to develop the input-output model describing the flowback water volume and TDS concentration with time. With the assumptions mentioned above, the cumulative volume of flowback water is a function of the volume of injected fluid and time, while the TDS concentration is only a function of time. To simplify the model, we considered the recovery ratio instead of the cumulative volume; in particular, the recovery ratio is defined as the ratio of the generated wastewater volume to the injected fluid 
volume, as shown in Eq. 92. Using a regression technique, natural logarithm function is applied to represent the relationships between the characteristics of flowback water and time, which are shown in Figure B.2 and B.3 in Appendix B. The corresponding regression model is presented as follows:

$$
\begin{aligned}
& y_{n, t}^{\text {well_out }}=\frac{Q_{n, t}^{\text {well_out }}}{Q_{n, t}^{\text {injected }}}, \quad \forall n, \forall t \in[1,90] \\
& y_{n, t}^{\text {well_out }}=0.0575 \ln (t)+0.0877, \forall n, \forall t \in[1,90] \\
& C_{n, t}^{\text {well_out }}=43134.79 \ln (t)+28925.13, \forall n, \forall t \in[1,90]
\end{aligned}
$$

where $t$ is in days from the moment of hydraulic fracturing is completed, $Q^{\text {injected }}$ is the total volume of the injected water for one fractured well, $Q_{n, t}^{\text {well_out }}$ is the cumulative volume of the generated wastewater in well $n$ in time period $t$ and $y_{n, t}^{\text {well_out }}$ and $C_{n, t}^{\text {well_out }}$ are the cumulative recovery ratio and the TDS concentration in well $n$ in time period $t$, respectively. It is noted that since the input-output model is developed based on the regression technique, the obtained model's validity should be constrained by the sampled data; specifically, the developed model can be applied within the range from approximate 20,000 to $150,000 \mathrm{BBL}$ for the volume of injected fracturing fluid.

Assuming that the returned formation water is neglected and the characteristics of the flowback water (i.e., essentially produced water) follow the trend over the first 90 days, the cumulative recovery ratio profile and the TDS concentration profile of the wastewater recovered over the first year are shown in Figure 4.1 and Figure 4.2. 


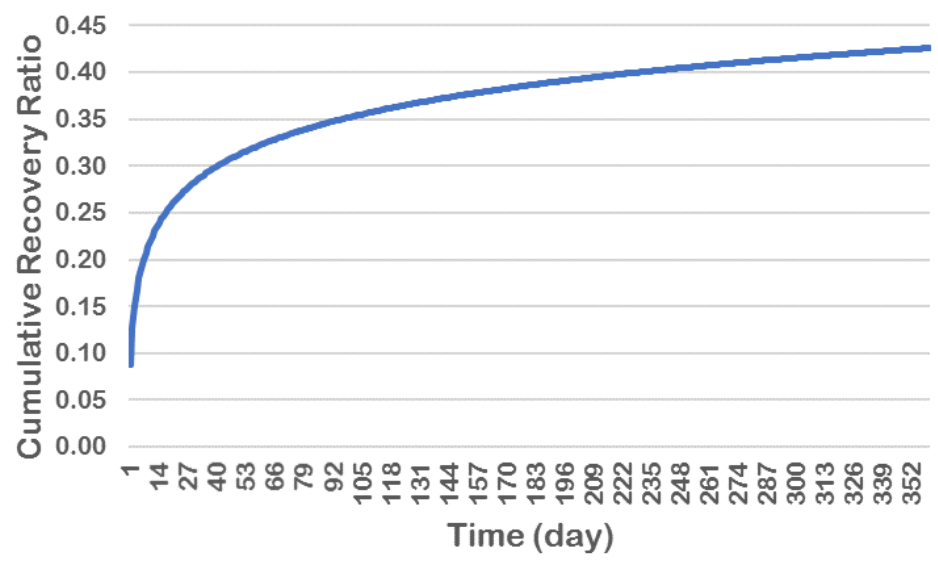

Figure 4.1 Cumulative recovery ratio of the wastewater recovered over the first year

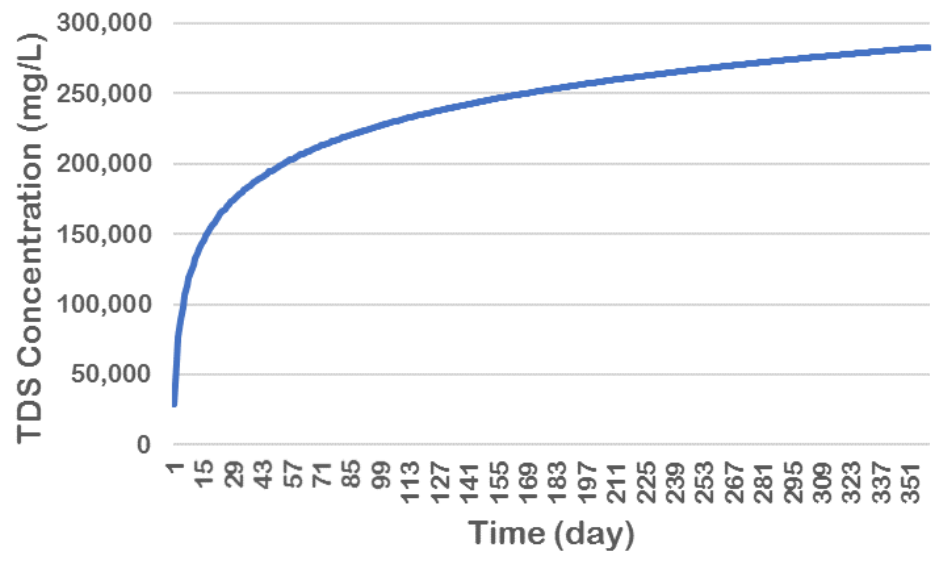

Figure 4.2 TDS concentration profile of the wastewater recovered over the first year

The recovery ratio on day 14 is around 0.24 which is close to the average recovery ratio provided in the report. On day 360 , it reaches nearly 0.42 which is comparable to the recovery ratio at location $\mathrm{D}$ and $\mathrm{E}$ on day 90 from Hayes et al. ${ }^{35}$ On the other hand, the TDS concentration on day 90 is $220,000 \mathrm{mg} / \mathrm{L}$ and it reaches $280,000 \mathrm{mg} / \mathrm{L}$ on day 360 which is close to the median TDS values of $278,000 \mathrm{mg} / \mathrm{L}$ presented in the work of Rowan et al. ${ }^{37}$ 
Thus, once the flowrate and TDS concentration profiles are obtained from the databased dynamic input-output model, they will be used as the inputs to the wastewater management optimization model. To verify the proposed MINLP optimization model's effectiveness and reliability, two case studies are presented. Specifically, Case 1 refers to a small-scale management process while Case 2 refers to a large-scale one which mimics a field case that contains multiple wells.

REMARK 5. The assumptions made in developing the dynamic input-output model can be relaxed. As for the first assumption, a detailed model with clear physical meaning can be developed based on some shale formation properties such as the permeability and porosity, which is able to explicitly interpret the significant difference in the wastewater characteristics between different locations. As for the second assumption, since the TDS concentration is generally used to determine the quality of wastewater and the data on day 0 represents the additives in the fracturing fluid, it is appropriate to assume that only the TDS coming from the shale formation is considered. As for the third assumption, it can be relaxed if the proppant concentration of the injected fracturing fluid is available; otherwise, it is an appropriate assumption since more than $90 \%$ of the fracturing fluid is pure water.

\subsubsection{Case Study 1}

In Case 1, we considered one fractured well, one wastewater storage, one TMD system, one reused water tank and one rejected water tank. The time horizon is one year and the unit time period is a day. The main objective is to cost-effectively manage the 
wastewater generated from the post-fracturing process (i.e., after hydraulic fracturing is completed).

With the developed input-output model, the cumulative volume of wastewater generated within the first year can be obtained when the volume of injected fluid is given; then, it can be converted to the flowrate in each day. The TDS concentration of the wastewater within the first year is also obtained and it can be converted to the weight fraction by assuming that the wastewater density is constant as $1000 \mathrm{~kg} / \mathrm{m}^{3}$. In this case, the volume of injected fluid is considered to be $70,000 \mathrm{BBL}$. Thus, the flowrate and the TDS weight fraction profiles are generated as shown in Figure 4.3 and 4.4.

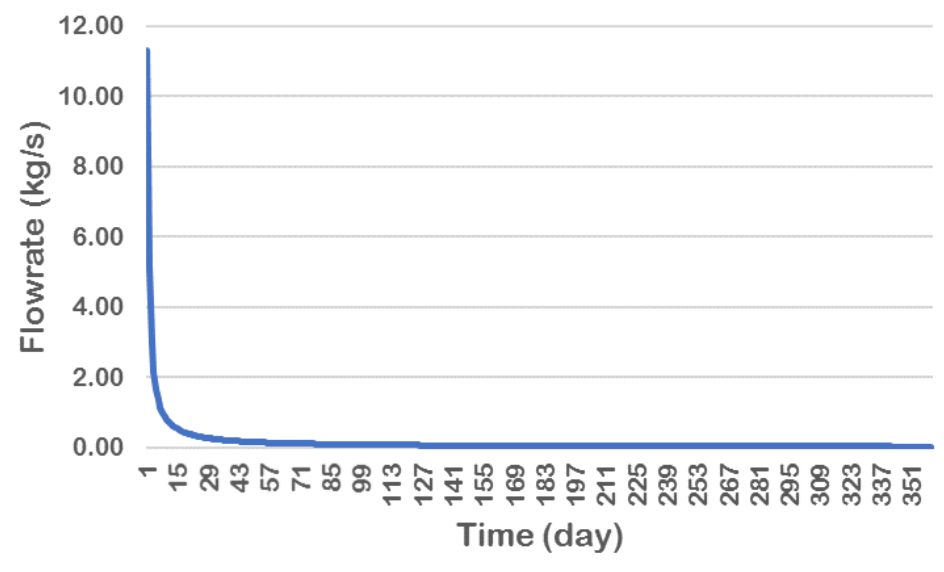

Figure 4.3 Flowrate profile of the wastewater recovered over the first year 


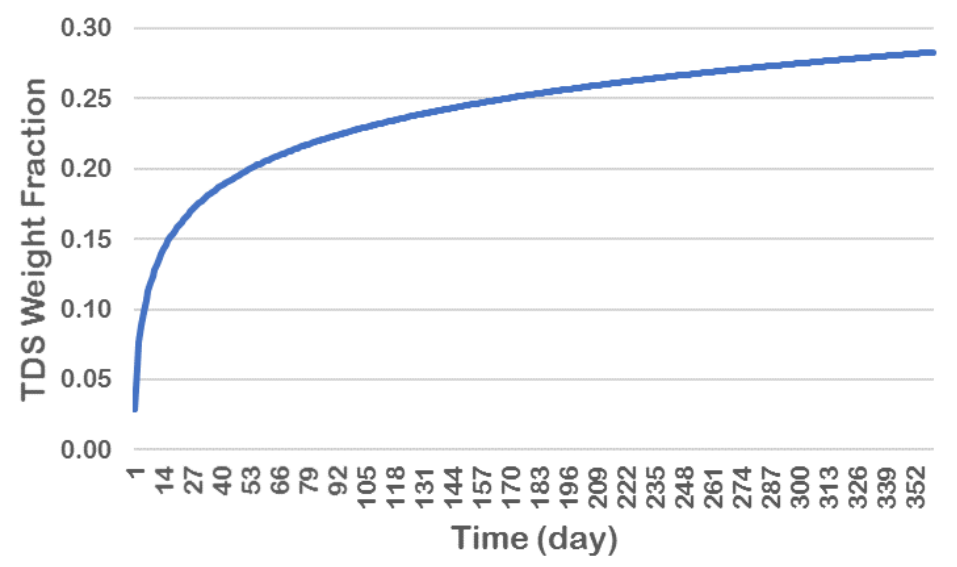

Figure 4.4 TDS weight fraction profile of the wastewater recovered over the first year

The parameters and the cost coefficients used in the wastewater management optimization model are given in Table C.1 in Appendix C. Since we only considered a single unit for each process in Case 1, the binary variables mentioned in Section 3.1.1 can be removed, which transforms the model from MINLP to NLP. The resultant NLP model consists of 12977 continuous variables and 18379 equations. Implemented in General Algebraic Modeling System (GAMS), it is solved using a global optimization solver $\left(\mathrm{ANTIGONE}^{38}\right.$ ) on an Intel $3.4 \mathrm{GHz}$ Core i7 CPU machine with $16 \mathrm{~GB}$ memory.

To deal with the large computational requirements due to the excessive input data points, we combined the data by month and regenerate 12 data points (i.e., in months) instead of 360 data points (i.e., in days). Using the combined data as the input, the complexity of the NLP model is effectively reduced as observed in Table 4.1. It is noted that since the solver ANTIGONE always reformulates the given model and detects the special structure before initializing the branch-and-bound global optimization algorithm, the provided computational statistics are obtained after the pre-processing. ${ }^{38}$ Through the 
solver ANTIGONE, the global optimal solution for wastewater management in Case 1 is obtained. The results are provided in Table C.2 and C.3 in Appendix C. Some results for design variables and costs are presented in Table 4.2.

Table 4.1 Comparison of computational statistics in Case 1.

\begin{tabular}{|c|c|c|}
\hline & 360 data points & Combined 12 data points \\
\hline $\begin{array}{c}\text { No. of continuous } \\
\text { variables }\end{array}$ & 4320 & 144 \\
\hline $\begin{array}{c}\text { No. of nonconvex } \\
\text { nonlinear equations }\end{array}$ & 5033 & 161 \\
\hline No. of nonlinear terms & 4317 & 42.52 \\
\hline CPU time (s) & No solution returned & 141 \\
\hline
\end{tabular}

Table 4.2 Design variables and costs for wastewater management in Case 1.

\begin{tabular}{|c|c|}
\hline Variable & Value \\
\hline Capacity of wastewater storage (kg) & $2.89 \times 10^{6}$ \\
\hline Capacity of reused water tank (kg) & $2.62 \times 10^{5}$ \\
\hline Capacity of rejected water tank (kg) & $2.31 \times 10^{5}$ \\
\hline Membrane area of TMD system $\left(\mathrm{m}^{2}\right)$ & 393 \\
\hline Profit from reusing water (\$/year) & 5,890 \\
\hline TOC (\$/year) & 63,106 \\
\hline TCC (\$/year) & 37,565 \\
\hline TAC (\$/year) & 94,781 \\
\hline
\end{tabular}

As shown in Table 4.2, the optimized wastewater management associated with Case 1 leads to a total annual cost of $\$ 94,781$, with $\$ 63,106$ in operating cost, $\$ 37,565$ in 
capital cost and $\$ 5,890$ from utilization of the reused water during the first year. As shown in Table C. 2 in the Appendix C, it is observed that the costs associated with the treatment unit account for a large proportion in both the operating and capital cost. Specifically, the total cost associated with the TMD system, which is $\$ 44,761$, makes up around $47 \%$ of the total annual cost. Due to the constraints considered in this work that the complete rejection is assumed in the TMD system and all the generated wastewater is required to be treated before the next step, the TMD system is the most important part that contributes to the total cost in wastewater management.

As mentioned, the initially generated water is characterized by a high flowrate and a low TDS concentration. Then, the flowrate decreases while the TDS concentration increases over time. Thus, there are two extreme approaches to manage the wastewater. One is to treat nearly all of the wastewater generated in each month. In this approach, during the first few months, most of the wastewater can be treated with a relatively low operating cost because of the low TDS concentration. Although the unit operating cost becomes high with the TDS concentration, the total operating cost required during the last few months is not high since the flowrate is insignificant. The only problem is that since the flowrate in the first month is extremely high, the membrane area required in the TMD system should be large, which in turn increases the capital cost in the treatment unit. Another approach is to store most of the wastewater generated in the first few months. Thus, the wastewater recovered in different time periods can be blended in the storage unit. Since the volume of the initially generated wastewater is extremely large, even though the TDS concentration of the wastewater in the last few months is high, the final 
TDS concentration of the mixture leaving the storage can be reduced, which decreases the unit operating cost. The only problem is that the required capacity of the storage unit should be large, which in turn increases the capital cost in the storage unit.

Based on the results for the flowrate and TDS weight fraction for the streams around units, which are shown in Table C.3 in Appendix C, the second method is chosen in this Case 1 and the comparisons of the flowrate and the TDS weight fraction before and after storage unit are presented in Figure 4.5 and 4.6. It illustrates that, with the storage unit, the flowrate of the streams leaving the storage is nearly the average value and the TDS weight fraction of the mixed streams is nearly reduced by half. Even though in the first month, nearly $90 \%$ of the generated wastewater is stored, which makes the capacity of the storage really large, it is still preferred since the capital cost in the storage unit is much less than the capital cost in the TMD system and the capital cost in the TMD system can be effectively reduced through this behavior.

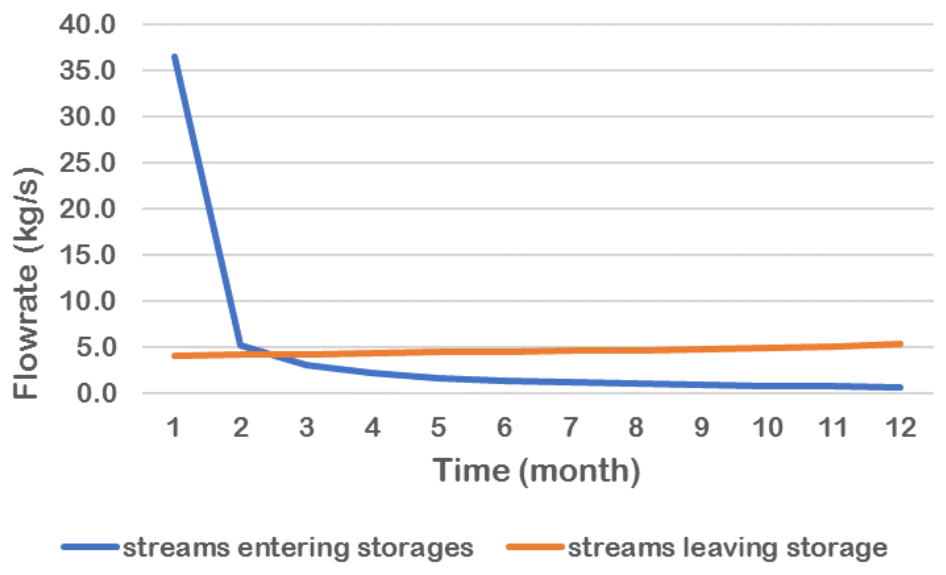

Figure 4.5 Comparison of flowrate of the streams entering and leaving the storage 


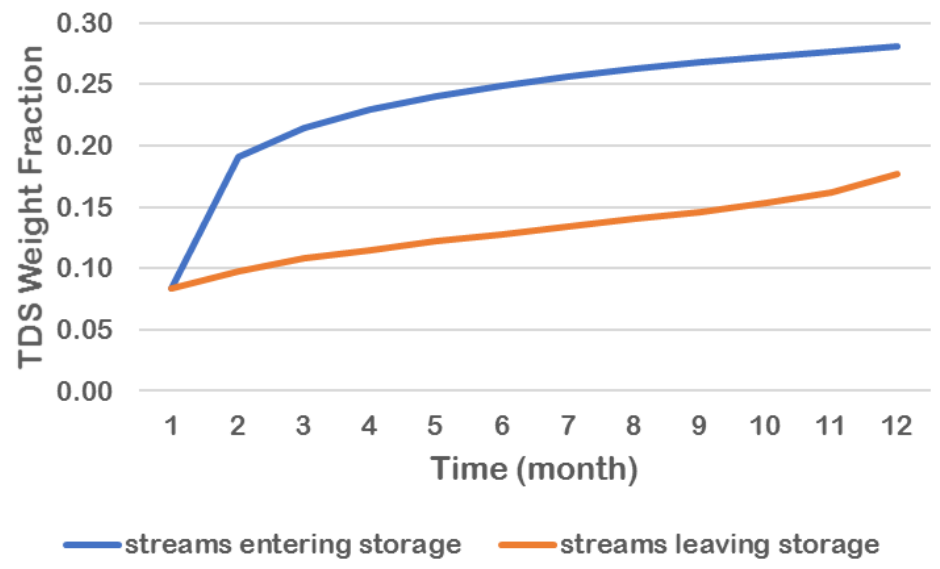

Figure 4.6 Comparison of TDS weight fraction of the streams entering and leaving the storage

As for the performance of the TMD system, the comparisons of the flowrate in the permeate streams and concentrate streams are presented in Figure 4.7 and 4.8. Since the complete rejection in the permeate side is assumed and the weight fraction of TDS in the concentrate streams should not exceed 0.35 , the optimal condition should be achieved by treating the wastewater as much as possible. Based on the optimal solution, the TDS weight fractions of the concentrate streams in all time periods are 0.35 , reaching the upper limit. As time goes on, the flowrate of the treated water entering the disposal unit increases while the flowrate of the treated water entering the reuse unit decreases. Specifically, at the beginning, around $76 \%$ of the wastewater can be reused, but at the end, only $49 \%$ can be reused. 


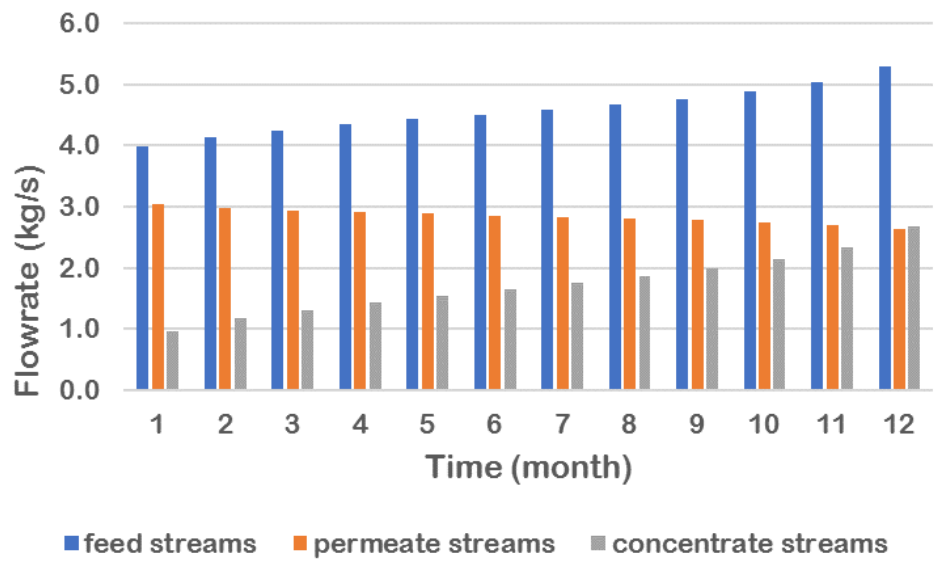

Figure 4.7 Flowrate of the feed, permeate and concentrate streams around TMD system

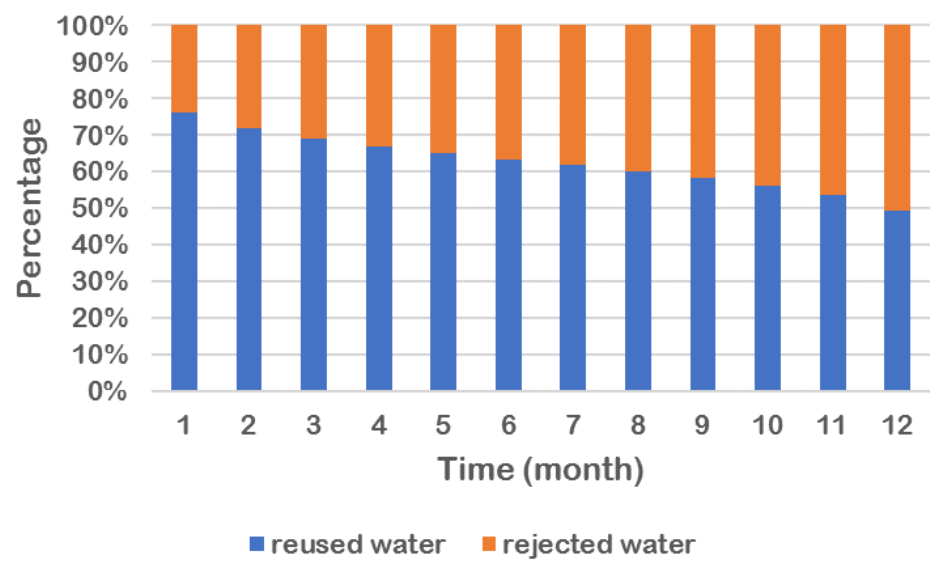

Figure 4.8 Percentage of the reused and rejected water around TMD system

\subsubsection{Case Study 2}

Another large-scale case study (Case 2) is presented considering six wells, which is the optimum number of wells determined by the section-based optimization method in Section 3.2.1. Meanwhile, multiple storage, reuse and disposal units are available to handle the wastewater generated from multiple wells. Unlike the mentioned pumping schedule, which is used for hydraulic fracturing operation to achieve the desired fracture 
geometry, the scheduling problem which is generally considered in the context of upstream oil and gas application refers to a schedule (i.e., sequence) of drilling wells and performing hydraulic fracturing jobs. In this work, we do not actually investigate the optimum schedule for the six wells to be fractured but have a brief discussion based on the results from one trivial schedule. That is, all of the six wells were fractured at the same time. Note that the time horizon considered is still one year. With the parameters provided in Table C.1 in the Appendix C, the resultant MINLP optimization model is solved through ANTIGONE and the optimal results are provided in Table C.4 and C.5 in Appendix C. Some important results are presented in Table 4.3. Note that the results obtained by multiplying the results from Case 1 by six are also provided for comparison.

Table 4.3 Design variables and costs for wastewater management in Case 2.

\begin{tabular}{|c|c|c|}
\hline Variable & Case 2 & Case $\mathbf{1} \times \mathbf{6}$ \\
\hline Computational time (s) & 10,831 & 58 \\
\hline Optimum number of wastewater storages & 2 & 1 \\
\hline Optimum number of reused water tanks & 1 & 1 \\
\hline Optimum number of rejected water tanks & 1 & 1 \\
\hline Capacity of wastewater storage $(\mathbf{k g})$ & $5.21 \times 10^{6} ;$ & $1.73 \times 10^{7} ;$ \\
\hline Capacity of reused water tank $(\mathbf{k g})$ & $1.20 \times 10^{7}$ & - \\
\hline Capacity of rejected water tank $(\mathbf{k g})$ & $9.48 \times 10^{5}$ & $1.39 \times 10^{6}$ \\
\hline Membrane area of TMD system $\left(\mathbf{m}^{\mathbf{2}}\right)$ & 2357.5 & 2355.7 \\
\hline
\end{tabular}


Table 4.3 Continued

\begin{tabular}{|c|c|c|}
\hline Variable & Case 2 & Case $\mathbf{1} \times \mathbf{6}$ \\
\hline Capital cost for storage unit (\$/year) & 12,841 & 16,932 \\
\hline Capital cost for treatment unit (\$/year) & 168,500 & 168,396 \\
\hline Capital cost for reuse unit (\$/year) & 1,991 & 6,990 \\
\hline Capital cost for disposal unit (\$/year) & 6,480 & 33,072 \\
\hline TAC (\$/year) & 533,112 & 568,686 \\
\hline
\end{tabular}

Computational time is not multiplied by six

As shown in Table 4.3, comparing to the results shown in Case 1, the obtained capacities and membrane area become really large (i.e., nearly six times the capacity in Case 1). However, with the cost coefficients applied in the capital cost formulations for storage, reuse and disposal units (i.e., Eqs. 56-58), the corresponding capital costs do not change significantly comparing to other costs.

In this work, since it is assumed that all the reused water is directly sold in the market for profit instead of being reintroduced for other wells to create fractures, applying different schedules will only directly affect the wastewater management but not the hydraulic fracturing process. Note that the total shale gas production may change if the time horizon is extended due to the schedule or a higher net profit can be achieved through MPC system. When applying different schedules to create the multiple wells, since the flowrate and TDS concentration of wastewater collected each day depend on the schedule of wells, the capacity of the storage, reuse and disposal units as well as the membrane area 
of the TMD system will change and thus the total capital cost will change. However, since the number of wells is fixed and all six wells have same flowrate and TDS concentration profiles, the total volume of generated wastewater is independent of well schedule, and thus, the total operating cost will not change.

In this work, considering that the computational cost in Case 2 is much higher (i.e., $10,831 \mathrm{~s}$ ) and the final simulation results will not change significantly even if the nontrivial scheduling problem for multiple wells is considered, we decide to focus on one fractured well to demonstrate the proposed framework.

\subsection{Modeling of Hydraulic Fracture}

As mentioned, the square drainage area is $A_{\text {section }}=2.59 \times 10^{6} \mathrm{~m}^{2}$. Based on the section-based optimization method, the number of wells and the number of fractures in one well were determined to be 6 and 55, respectively. Thus, the length of a side of the section is $1609.35 \mathrm{~m}$ and the section is divided into 330 subsections using Eq. 61. For each subsection, the length is $268.22 \mathrm{~m}$ and the width is $29.26 \mathrm{~m}$. Assuming the fracture height is the same as the reservoir thickness $H_{r}=60 \mathrm{~m}$, the numerical model of the onewing fracture is designed with a dimension of $29.26 \mathrm{~m} \times 135 \mathrm{~m} \times 60 \mathrm{~m}$. Since the optimum propped fracture half-length is $x_{f}=120 \mathrm{~m}$ and the average propped width is $W_{o p t}=2.9 \mathrm{~mm}$, the dimension is refined in I and $\mathrm{J}$ direction and the resulting dimension of each grid is $9.75 \mathrm{~m} \times 5 \mathrm{~m} \times 60 \mathrm{~m}$. Figure 4.9 and 4.10 represent the $2 \mathrm{D}$ and $3 \mathrm{D}$ model of the one-wing fracture. As shown in the 3D model, the black line along the $\mathrm{J}$ coordinate but in the opposite direction represents the fracture with the desired geometry. 


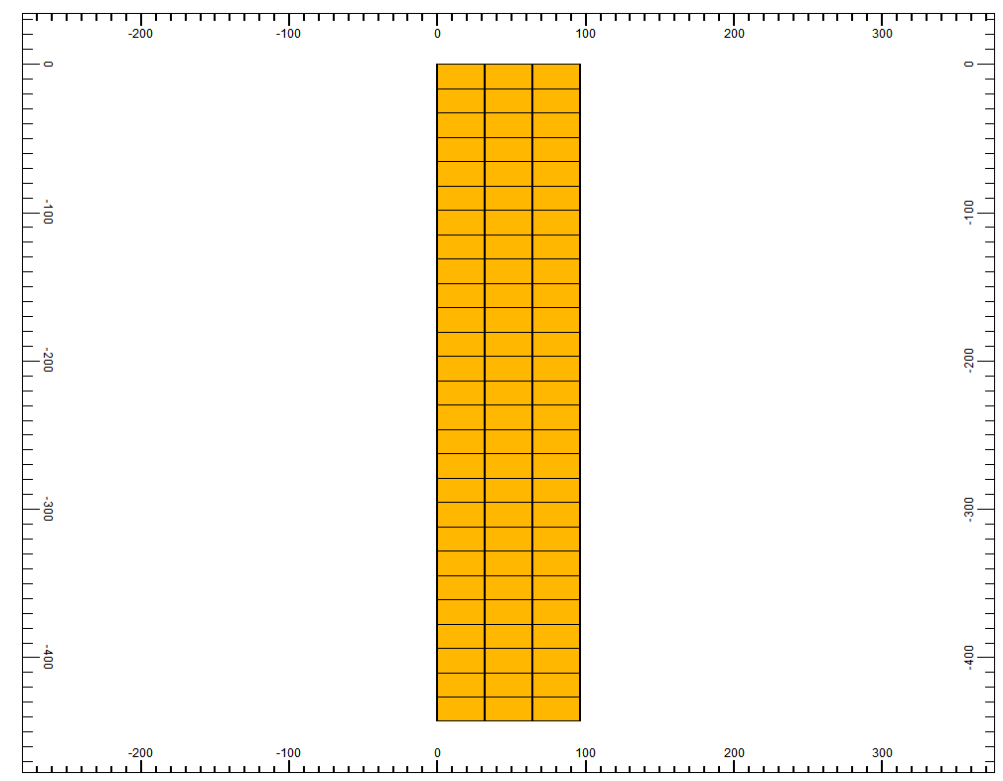

Figure 4.9 2D model of the one-wing fracture in CMG

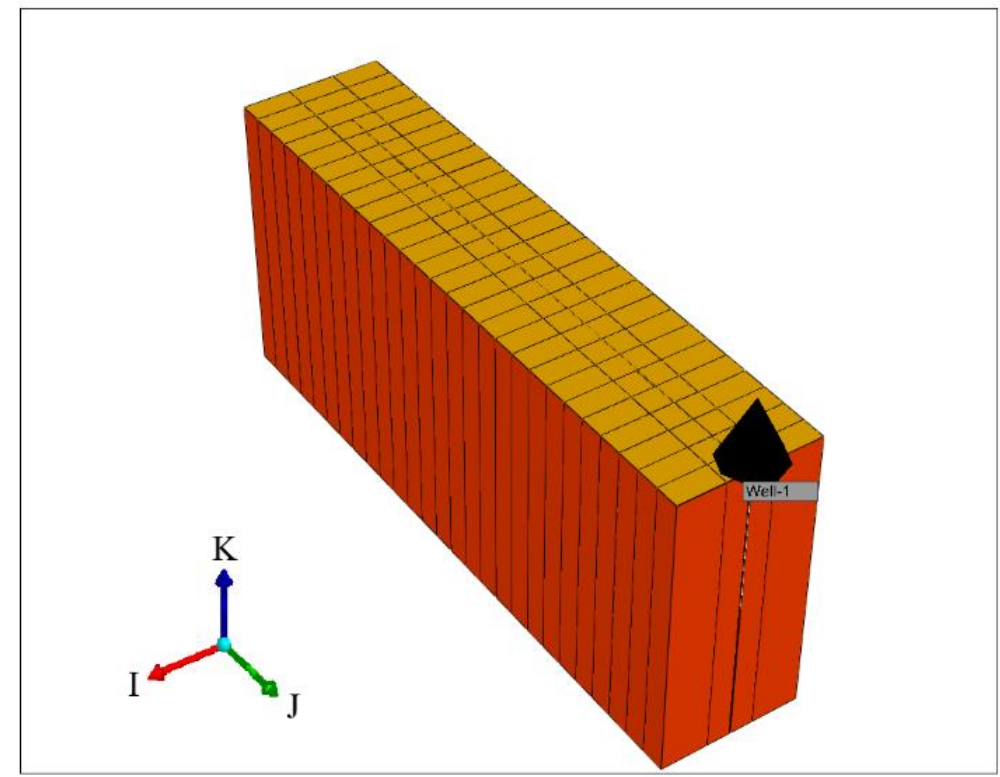

Figure 4.10 3D model of the one-wing fracture in CMG

The detailed shale and fracture properties of the Marcellus Shale well are provided in Table D.1 in Appendix D, which are used for the simulation work in CMG. With the 
given parameters, when the propped fracture half-length is $120 \mathrm{~m}$, the cumulative shale gas production profile and the shale gas flowrate profile for the one-wing fracture model are presented in Figure 4.11 and 4.12. Note that the generated profiles through CMG are the production forecasts for a thirty-year period. Considering that the market selling price of the shale gas production is $\$ 3 /$ MMBTU, the revenue from selling produced shale gas is calculated. Specifically, when the propped fracture half-length is $120 \mathrm{~m}$, the total shale gas production per well within the first year is $1003.2 \mathrm{MMFT}^{3}$ and the corresponding total revenue is $\$ 3.13 \mathrm{MM}$. Comparing with the field data provided by $\mathrm{Yu}$ et al. ${ }^{39}$, which is about $500 \mathrm{MMFT}^{3}$, the main reason for the difference is that the number of fractures per well in our case is nearly twice as many as the one in their work.

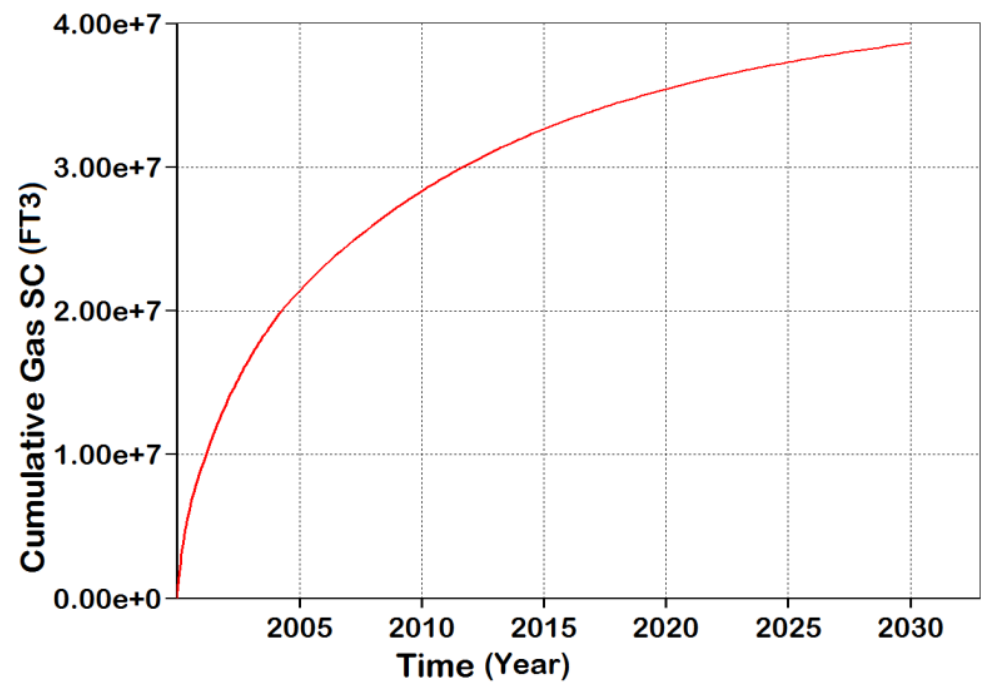

Figure 4.11 Cumulative gas production for $120 \mathrm{~m}$ one-wing fracture 


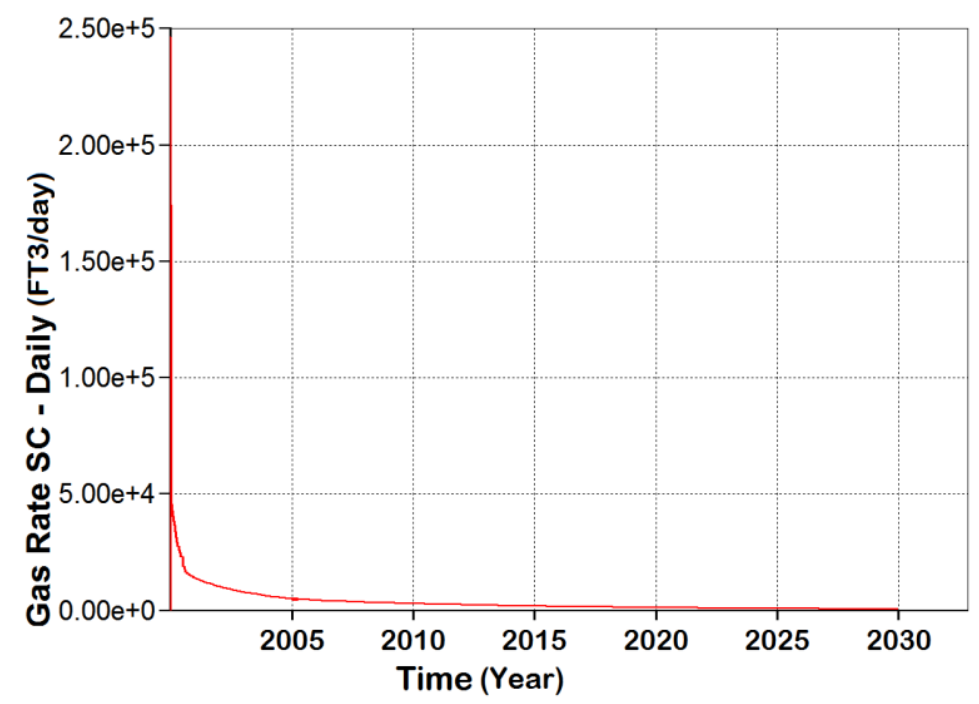

Figure 4.12 Gas flowrate for $120 \mathrm{~m}$ one-wing fracture

On the other hand, Figure 4.13 shows the pressure distributions for the same fracture presented in Figure 4.10 after 8, 12 and 16 months of field production. When the fracture is initially created, the pressure from the trapped oil and gas around the fracture is high. As time goes on, the pressure around the fracture will decrease continuously since the oil and gas are extracted. Generally, if the oil and gas pressure is high enough, there will be no interaction between the neighboring fractures. As shown in Figure 4.13, it is observed that the pressure at the edge of the subsection is still as high as around $4300 \mathrm{psi}$ at $\mathrm{t}=12$ months. Note that the initial reservoir pressure is 5024 psi as given in Table D. 1 in Appendix D. Thus, it illustrates that the interaction can be neglected and it is feasible to approximate the total shale gas production by the simulation result from the one-wing fracture model multiplied by the number of one-wing fractures. 


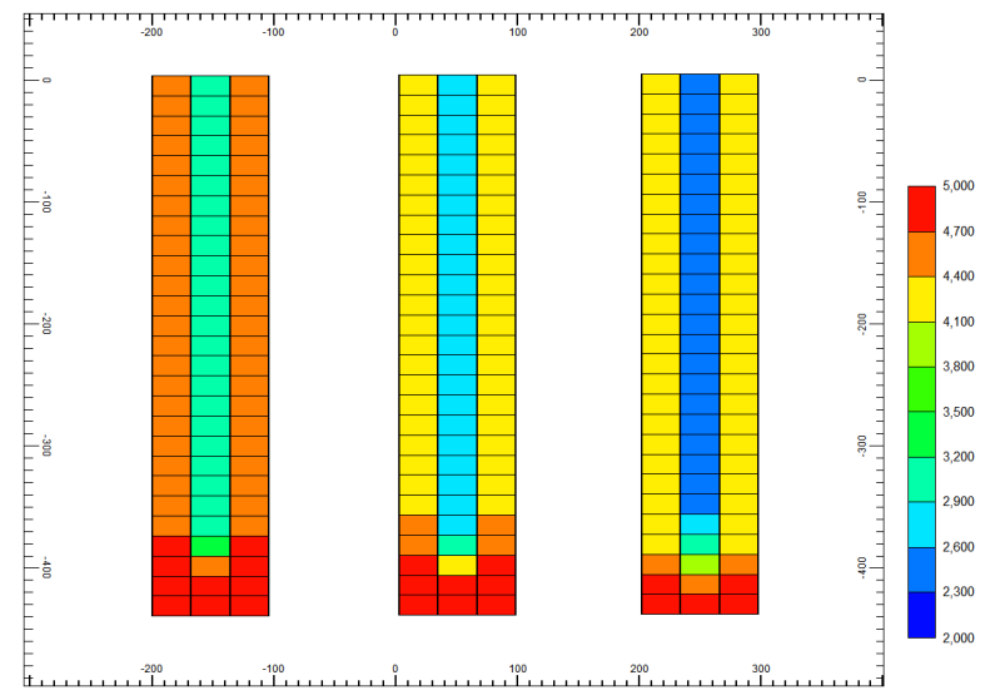

Figure 4.13 Pressure distribution after 8, 12, 16 months production for $120 \mathrm{~m}$ onewing fracture

\subsection{Proposed Mapping-based Control of Hydraulic Fracturing}

\subsubsection{Construction of Maps}

In the modeling of wastewater management, it is observed that the accumulative recovery ratio profile and the TDS weight fraction profile are fixed since they are only a function of time as shown in Eqs. 93-94. However, when the volume of injected fracturing fluid changes, the flowrate of the generated wastewater in each day changes as well as the associated total annual cost. In this regard, a series of injected fracturing fluid volumes are applied to the optimization model to generate input/output data, some of which are presented in Table B.3 in Appendix B. Then, the map representing the relationship between the minimized total annual cost and the volume of injected fluid as generated is shown in Figure 4.14.

In the modeling of hydraulic fracture, assuming the reservoir parameters and the operating conditions are constant, the shale gas production is a function of the final 
fracture geometry. Since the propped fracture height is assumed to be the same as the reservoir height and the average propped width is fixed at its optimum value, the gas production changes only with the propped fracture half-length. In this regard, a series of propped fracture half-lengths are applied to CMG to generate input/output data, some of which are presented in Table D.2 in Appendix D. Then, the map representing the relationship between the total revenue from selling produced shale gas and the propped fracture half-length as generated is shown in Figure 4.15.

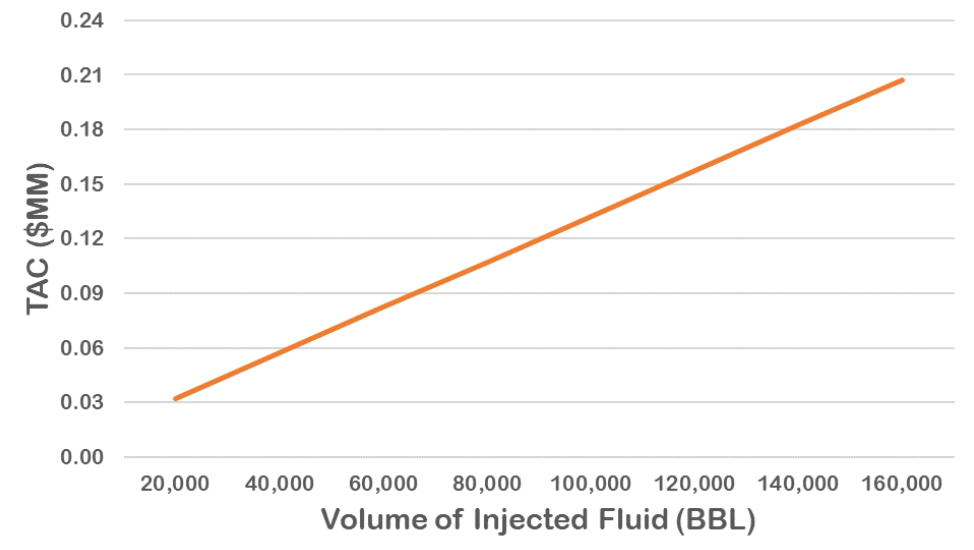

Figure 4.14 Map from optimization model of wastewater management for different scenarios 


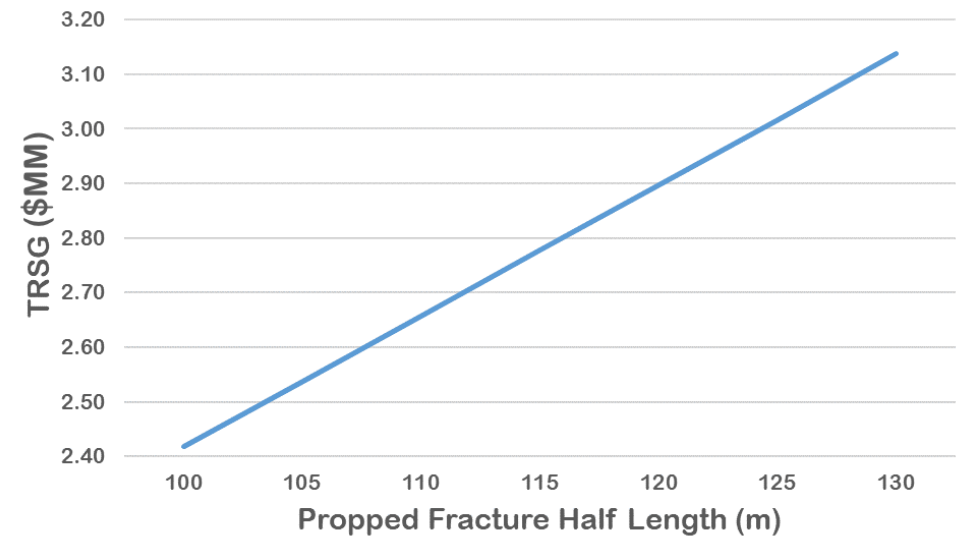

Figure 4.15 Map obtained from CMG reservoir simulation of one-wing fracture for different scenarios

Based on a simple linear regression method, the relationships shown in Figure 4.14 and 4.15 are presented using Eqs. 95-96, which are then used in the MPC formulation.

$$
\begin{aligned}
& T A C=\left(1.2512 Q^{\text {injected }}+7200\right) \times 10^{-6} \\
& T R S G=0.0240 x_{f}+0.0198
\end{aligned}
$$

\subsubsection{Model-based Feedback Controller}

In this reservoir example, the given total proppant amount is $M_{\text {prop }}=2.409 \times$ $10^{7} \mathrm{~kg}$ and the optimum propped fracture half-length is $x_{f}=120 \mathrm{~m}$. Thus, the amount of the proppant injected for one fracture is $M_{\text {prop }, f}=7.3 \times 10^{4} \mathrm{~kg}$. Provided that the proppant particle density is $\rho_{p}=2648 \mathrm{~kg} / \mathrm{m}^{3}$, proppant bank porosity is $\phi=0.61$ and equilibrium proppant bank height is $h_{e q}=54 \mathrm{~m}$, the optimal average fracture width at the end of pumping is calculated to be $W_{\text {avg,target }}=5.37 \mathrm{~mm}$ using Eq. 90 . In the closedloop simulation, the pad time is fixed to be $800 \mathrm{~s}$, during which water is injected without proppant. Then, the fracturing fluid is injected following the pumping schedule, 
meanwhile the control framework and the Kalman filter are initialized. The whole operation process is divided into nine stages and the operation time in each stage is $500 \mathrm{~s}$. In each simulation period, the real-time measurements of the fracture width at the wellbore and the fracture length are known beforehand and then used to estimate the unmeasurable average fracture width through the Kalman filter. At the same time, the flowrate and proppant concentration in each stage are determined by solving the optimization problem to maximize the net profit. This procedure will be repeated until the end of the hydraulic fracturing process. Since the Kalman filter is updated iteratively based on the difference between the predicted value and the measured value, the estimated average fracture width becomes more accurate; otherwise, its measurement is not available.

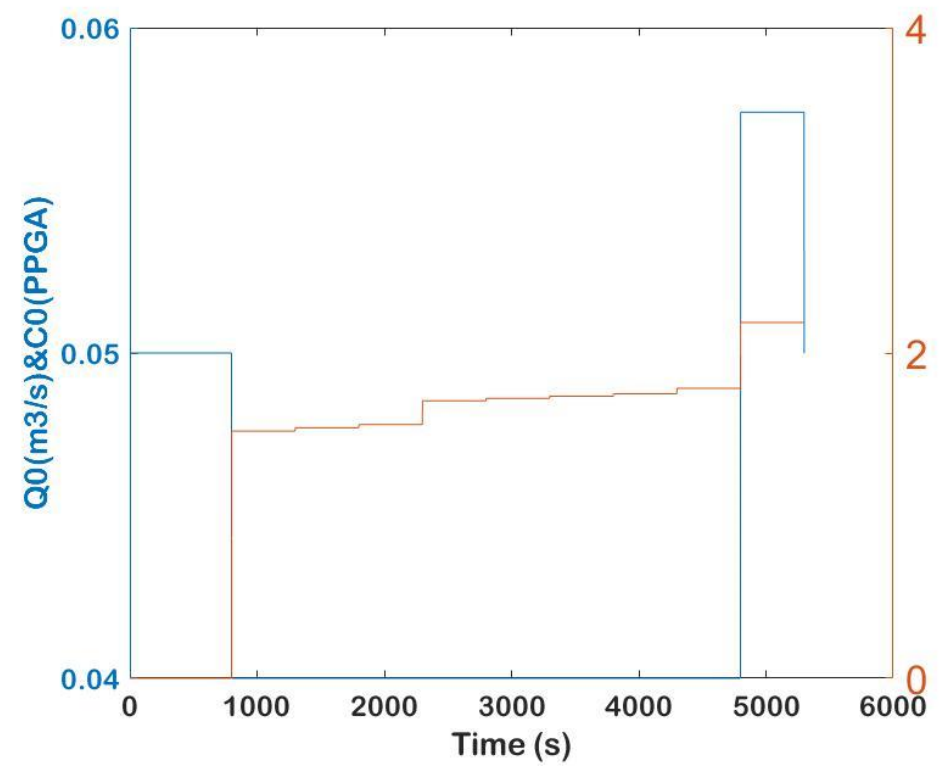

Figure 4.16 Optimal pumping schedule for shale gas production. 


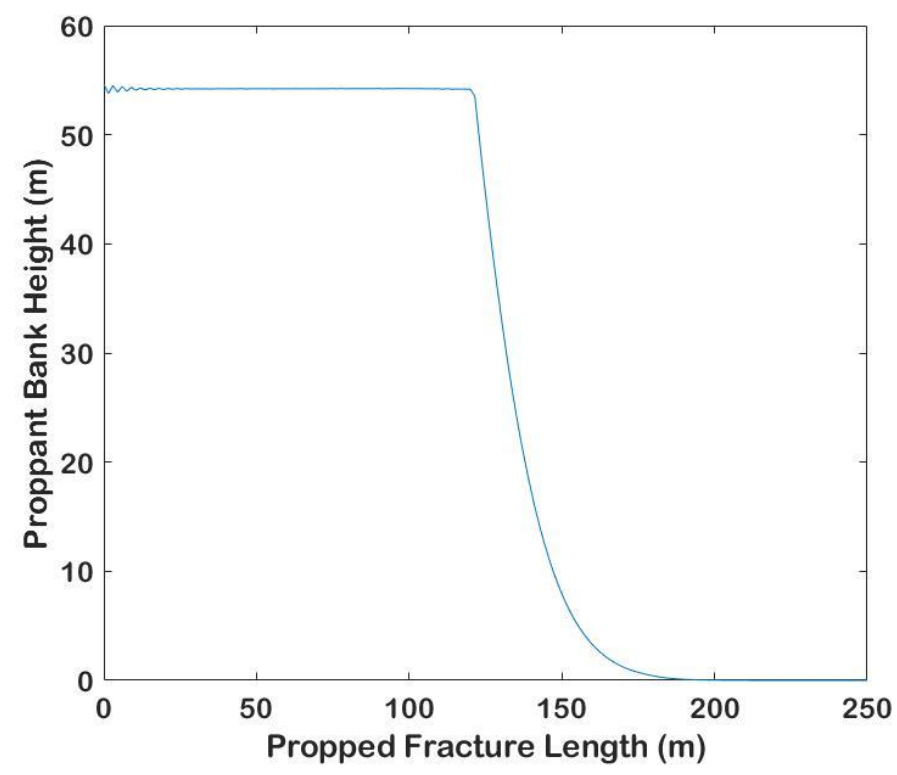

Figure 4.17 Proppant bank height profile during hydraulic fracturing process

Applying the proposed MPC formulation discussed in Section 3.2.5 and assuming that the unit cost of the freshwater $\left(U C^{\text {fresh }}\right)$ is the same as the selling price of the reused water $\left(U P^{r e u s e}\right)$ provided in Table C.1 in Appendix C, the obtained pumping schedule and proppant bank height are shown in Figure 4.16 and 4.17. It is observed that the flowrate of the injected fracturing fluid is always at the minimum level except the last stage while the proppant concentration monotonically increases and eventually reaches the maximum in the last stage. This pumping schedule helps reduce the volume of the injected freshwater while achieving the uniform proppant bank height across the desired optimum propped fracture half-length. With the obtained pumping schedule, the corresponding net profit from one horizontal well for the first year is about \$2.703 MM. Other details are provided in Table 4.4 . 
For comparison purposes, the total revenue, total cost associated with wastewater management and injected freshwater are calculated based on the pumping schedule provided by Siddhamshetty et al. ${ }^{23}$ It shows in Table 4.4 that, with the proposed control framework, a nearly $11 \%$ reduction in the total volume of the injected freshwater is achieved, which results in that the net profit from one fractured well increases by $\$ 0.029$ MM. In addition, another case with 5\% reduction in the total amount of proppant is also presented in Table 4.4. As shown, when the proppant amount is less, both the propped fracture half-length and injected freshwater amount decrease. Thus, the total revenue as well as the total cost from managing wastewater and from purchasing freshwater decreases. Since the change in the revenue is much more than that of the cost, the net profit is reduced. However, if the proppant cost is considered here, this loss can be compensated for by purchasing less proppant as required.

Table 4.4 Closed-loop simulation results for one horizontal well.

\begin{tabular}{|c|c|c|c|}
\hline Variable & $\begin{array}{c}\text { Siddhamshetty } \\
\text { et al.23 }\end{array}$ & $\begin{array}{c}\text { Our work } \\
\left(\boldsymbol{M}_{\text {prop, }}=\right. \\
\mathbf{3 6 5 0 0})\end{array}$ & $\begin{array}{c}\text { Our work } \\
\left(\boldsymbol{M}_{\text {prop,f }}=\right. \\
\mathbf{3 4 7 0 0})\end{array}$ \\
\hline $\begin{array}{c}\text { Proppant amount for half- } \\
\text { fracture (kg) }\end{array}$ & 36,500 & 36,500 & 34,700 \\
\hline $\begin{array}{c}\text { Propped fracture half-length } \\
\text { (m) }\end{array}$ & 121.8 & 121.8 & 115.8 \\
\hline $\begin{array}{c}\text { Injected pure water volume } \\
\text { (BBL) }\end{array}$ & 166,792 & 148,692 & 139,651 \\
\hline
\end{tabular}


Table 4.4 Continued

\begin{tabular}{|c|c|c|c|}
\hline Variable & $\begin{array}{c}\text { Siddhamshetty } \\
\text { et al. }\end{array}$ & $\begin{array}{c}\text { Our work } \\
\left(\boldsymbol{M}_{\text {prop, }}=\right. \\
\mathbf{3 6 5 0 0}\end{array}$ & $\begin{array}{c}\text { Our work } \\
\left(\boldsymbol{M}_{\text {prop, }}=\right. \\
\mathbf{3 4 7 0 0})\end{array}$ \\
\hline $\begin{array}{c}\text { Revenue from shale gas } \\
\text { (\$MM/year) }\end{array}$ & 2.943 & 2.943 & 2.800 \\
\hline $\begin{array}{c}\text { TAC from wastewater } \\
\text { management (\$MM/year) }\end{array}$ & 0.216 & 0.193 & 0.182 \\
\hline $\begin{array}{c}\text { Cost from freshwater } \\
\text { (\$MM/year) }\end{array}$ & 0.053 & 0.047 & 0.044 \\
\hline $\begin{array}{c}\text { Net profit (\$MM/year) } \\
\text { NMM }\end{array}$ & 2.674 & 2.703 & 2.573 \\
\hline
\end{tabular}

REMARK 6. The proposed framework is also applicable for a horizon with more than one year, such as ten years, which is usually considered in the literature. Generally speaking, nearly $10-25 \%$ of the total wastewater production of a well over 10 years is generated during the first 3 months as flowback water while 20-50\% is generated during the first 6 months. ${ }^{40}$ However, with different unconventional basins, the total generated wastewater volume can be significantly different. ${ }^{41}$ Also, due to the extension of production period (i.e., from one year to ten years), the total shale gas production will change significantly. Thus, the final simulation results may change. In order to apply the proposed framework for 10 years, the flowrate and TDS concentration profiles of wastewater generated after the first year are required. 


\section{CONCLUSION*}

In this work, a novel closed-loop control framework has been proposed for shale gas development utilizing maps that describe the total annual cost of wastewater management and the total revenue from shale production as functions of the amount of freshwater injected and the final fracture geometry, respectively. The goal is to balance a trade-off between hydraulic fracturing and water management by manipulating the pumping schedule. As a result, to inject the designated amount of proppant with less water, the volume of the freshwater injected was reduced by $11 \%$ while the desired fracture geometry was still achieved, leading to the theoretical maximum productivity. Once the hydraulic fracturing operation is completed, the generated wastewater was effectively treated by the TMD system and $62 \%$ of the treated wastewater was sold in the market for reuse. To reduce the high cost associated with the treatment process, the initially generated wastewater was stored and then blended with the wastewater generated later which allowed the TMD system to handle the wastewater with a lower TDS concentration. Considering that the reused water can be directly injected to other wells to further reduce the freshwater consumption in another hydraulic fracturing operation, the future work will study the potential benefit of reintroducing the treated water. Future work can also consider multiple treatment technologies and quantitatively study the environmental footprint of shale gas development

\footnotetext{
*Reprinted with permission from "Economic model-based controller design framework for hydraulic fracturing to optimize shale gas production and water usage" by Cao, K.; Siddhamshetty, P.; Ahn, Y.; Mukherjee, R. and Kwon, J. S. 2019. Ind. Eng. Chem. Res., 2019. Copyright 2019 American Chemical Society.
} 


\section{REFERENCES}

1. Administration, U. E. I., Annual energy outlook 2018 with projections to 2050. 2018.

2. Wang, Z.; Krupnick, A., A retrospective review of shale gas development in the United States: What led to the boom? Economics of Energy \& Environmental Policy 2015, 4, (1), 5-18.

3. Hughes, J. D., Energy: A reality check on the shale revolution. Nature 2013, 494, (7437), 307.

4. Acharya, H. R.; Henderson, C.; Matis, H.; Kommepalli, H.; Moore, B.; Wang, H., Cost effective recovery of low-TDS frac flowback water for re-use. DOE Report DEFE0000784 2011, 100.

5. Lira-Barragán, L. F.; Ponce-Ortega, J. M.; Guillén-Gosálbez, G.; El-Halwagi, M. M., Optimal water management under uncertainty for shale gas production. Industrial \& Engineering Chemistry Research 2016, 55, (5), 1322-1335.

6. Karapataki, C. Techno-economic analysis of water management options for unconventional natural gas developments in the Marcellus Shale. Massachusetts Institute of Technology, 2012.

7. Dunn, S., Fracking 101: Breaking down the most important part of today's oil, gas drilling. The Tribune, Greely and Weld County, Colorado 2016. 
8. Yang, L.; Grossmann, I. E.; Manno, J., Optimization models for shale gas water management. AIChE Journal 2014, 60, (10), 3490-3501.

9. Yang, L.; Grossmann, I. E.; Mauter, M. S.; Dilmore, R. M., Investment optimization model for freshwater acquisition and wastewater handling in shale gas production. AIChE Journal 2015, 61, (6), 1770-1782.

10. Gao, J.; You, F., Optimal design and operations of supply chain networks for water management in shale gas production: MILFP model and algorithms for the water- energy nexus. AIChE Journal 2015, 61, (4), 1184-1208.

11. Blewett, T. A.; Weinrauch, A. M.; Delompré, P. L.; Goss, G. G., The effect of hydraulic flowback and produced water on gill morphology, oxidative stress and antioxidant response in rainbow trout (Oncorhynchus mykiss). Scientific Reports 2017, 7, 46582.

12. Mauter, M. S.; Palmer, V. R., Expert elicitation of trends in Marcellus oil and gas wastewater management. Journal of Environmental Engineering 2014, 140, (5), B4014004.

13. Shaffer, D. L.; Arias Chavez, L. H.; Ben-Sasson, M.; Romero-Vargas Castrillón, S.; Yip, N. Y.; Elimelech, M., Desalination and reuse of high-salinity shale gas produced water: drivers, technologies, and future directions. Environmental Science \& Technology 2013, 47, (17), 9569-9583. 
14. Guan, G.; Wang, R.; Wicaksana, F.; Yang, X.; Fane, A. G., Analysis of membrane distillation crystallization system for high salinity brine treatment with zero discharge using Aspen flowsheet simulation. Industrial \& Engineering Chemistry Research 2012, 51, (41), 13405-13413.

15. McGinnis, R. L.; Hancock, N. T.; Nowosielski-Slepowron, M. S.; McGurgan, G. D., Pilot demonstration of the $\mathrm{NH} 3 / \mathrm{CO} 2$ forward osmosis desalination process on high salinity brines. Desalination 2013, 312, 67-74.

16. Li, M., Optimal plant operation of brackish water reverse osmosis (BWRO) desalination. Desalination 2012, 293, 61-68.

17. Li, M.; Noh, B., Validation of model-based optimization of brackish water reverse osmosis (BWRO) plant operation. Desalination 2012, 304, 20-24.

18. Oke, D.; Majozi, T.; Mukherjee, R.; Sengupta, D.; El-Halwagi, M., Simultaneous Energy and Water Optimisation in Shale Exploration. Processes 2018, 6, (7), 86.

19. Lopez Diaz, D. C.; Fernando Lira-Barragán, L.; Rubio-Castro, E.; You, F.; PonceOrtega, J., Optimal design of water networks for shale gas hydraulic fracturing including economic and environmental criteria. Clean Technologies and Environmental Policy 2018, 20, (10), 2311-2332.

20. Nolte, K., Determination of proppant and fluid schedules from fracturing-pressure decline. SPE Production Engineering 1986, 1, (04), 255-265. 
21. Gu, H.; Desroches, J. In New pump schedule generator for hydraulic fracturing treatment design, SPE Latin American and Caribbean petroleum engineering conference, Society of Petroleum Engineers 2003.

22. Dontsov, E.; Peirce, A., A new technique for proppant schedule design. Hydraul Fract J 2014, 1, (3).

23. Siddhamshetty, P.; Kwon, J. S.; Liu, S.; Valkó, P. P., Feedback control of proppant bank heights during hydraulic fracturing for enhanced productivity in shale formations. AIChE Journal 2018, 64, (5), 1638-1650.

24. Yang, S.; Siddhamshetty, P.; Kwon, J. S., Optimal pumping schedule design to achieve a uniform proppant concentration level in hydraulic fracturing. Computers \& Chemical Engineering 2017, 101, 138-147.

25. Siddhamshetty, P.; Yang, S.; Kwon, J. S., Modeling of hydraulic fracturing and designing of online pumping schedules to achieve uniform proppant concentration in conventional oil reservoirs. Computers \& Chemical Engineering 2018, 114, 306-317.

26. Siddhamshetty, P.; Wu, K.; Kwon, J. S., Optimization of simultaneously propagating multiple fractures in hydraulic fracturing to achieve uniform growth using data-based model reduction. Chemical Engineering Research and Design 2018, 136, 675686. 
27. Siddhamshetty, P.; Wu, K.; Kwon, J. S., Modeling and control of proppant distribution of multi-stage hydraulic fracturing in horizontal shale wells. Industrial \& Engineering Chemistry Research 2019.

28. Singh Sidhu, H.; Siddhamshetty, P.; Kwon, J. S., Approximate Dynamic Programming Based Control of Proppant Concentration in Hydraulic Fracturing. Mathematics 2018, 6, (8), 132.

29. Etoughe, P.; Siddhamshetty, P.; Cao, K.; Mukherjee, R.; Kwon, J. S., Incorporation of sustainability in process control of hydraulic fracturing in unconventional reservoirs. Chemical Engineering Research and Design 2018, 139, 62-76.

30. Elsayed, N. A.; Barrufet, M. A.; El-Halwagi, M. M., Integration of Thermal Membrane Distillation Networks with Processing Facilities. Industrial \& Engineering Chemistry Research 2014, 53, (13), 5284-5298.

31. Gregory, K. B.; Vidic, R. D.; Dzombak, D. A., Water management challenges associated with the production of shale gas by hydraulic fracturing. Elements 2011, 7, (3), 181-186.

32. Lawson, K. W.; Lloyd, D. R., Membrane distillation. Journal of Membrane Science 1997, 124, (1), 1-25.

33. Oh, H.-J.; Choung, Y.-K.; Lee, S.; Choi, J.-S.; Hwang, T.-M.; Kim, J. H., Scale formation in reverse osmosis desalination: model development. Desalination 2009, 238, (1-3), 333-346. 
34. Liu, S.; Valkó, P. P., Optimization of Spacing and Penetration Ratio for InfiniteConductivity Fractures in Unconventional Reservoirs: A Section-Based Approach. SPE Journal 2017, 22, (06), 1,877-1,892.

35. Hayes, T., Sampling and Analysis of Water Streams Associated with the Development of Marcellus Shale Gas. Gas Technology Institute 2009.

36. Siddhamshetty, P.; Kwon, J. S., Model-based feedback control of oil production in oil-rim reservoirs under gas coning conditions. Computers \& Chemical Engineering 2018, 112, 112-120.

37. Rowan, E. L.; Engle, M. A.; Kraemer, T. F.; Schroeder, K. T.; Hammack, R. W.; Doughten, M. W., Geochemical and isotopic evolution of water produced from Middle Devonian Marcellus shale gas wells, Appalachian basin, PennsylvaniaGeochemistry of Produced Water from Marcellus Shale Water, PA. Aapg Bulletin 2015, 99, (2), 181-206.

38. Misener, R.; Floudas, C. A., ANTIGONE: algorithms for continuous/integer global optimization of nonlinear equations. Journal of Global Optimization 2014, 59, (23), 503-526.

39. Yu, W.; Zhang, T.; Du, S.; Sepehrnoori, K., Numerical study of the effect of uneven proppant distribution between multiple fractures on shale gas well performance. Fuel 2015, 142, 189-198. 
40. Kondash, A. J.; Albright, E.; Vengosh, A., Quantity of flowback and produced waters from unconventional oil and gas exploration. Science of the Total Environment 2017, 574, 314-321.

41. Kondash, A.; Vengosh, A., Water footprint of hydraulic fracturing. Environmental Science \& Technology Letters 2015, 2, (10), 276-280.

42. Cao, K.; Siddhamshetty, P.; Ahn, Y.; Mukherjee, R.; Kwon, J.S., Economic model-based controller design framework for hydraulic fracturing to optimize shale gas production and water usage. Industrial \& Engineering Chemistry Research 2019. 


\section{APPENDIX A}

\section{SECTION-BASED OPTIMIZATION MODEL}

Table A Optimal design parameters used in shale reservoir

\begin{tabular}{|c|c|c|c|c|}
\hline $\boldsymbol{n}_{\boldsymbol{c}}$ & $\boldsymbol{n}_{\boldsymbol{r}}$ & $\boldsymbol{J}_{\boldsymbol{D}}$ & $\boldsymbol{J}_{\boldsymbol{D}, \text { well }}$ & $\boldsymbol{x}_{\boldsymbol{f}}(\mathbf{m})$ \\
\hline $\mathbf{4}$ & 83 & 137 & 34 & 119 \\
\hline $\mathbf{5}$ & 66 & 474 & 95 & 120 \\
\hline $\mathbf{6}$ & 55 & 2227 & 371 & 120 \\
\hline $\mathbf{7}$ & 56 & 2293 & 328 & 101 \\
\hline $\mathbf{8}$ & 57 & 2363 & 295 & 87 \\
\hline $\mathbf{9}$ & 58 & 2437 & 271 & 76 \\
\hline $\mathbf{1 0}$ & 59 & 2513 & 251 & 67 \\
\hline
\end{tabular}




\section{APPENDIX B}

DATA-BASED DYNAMIC INPUT-OUTPUT MODEL

Table B. 1 Water use and flowback water collection associated with hydraulic fracturing of shale gas wells.

\begin{tabular}{|c|c|c|c|c|c|c|c|}
\hline \multirow{2}{*}{ Location } & \multirow{2}{*}{$\begin{array}{l}\text { Well } \\
\text { Type }\end{array}$} & \multirow{2}{*}{$\begin{array}{c}\text { Total Vol. } \\
\text { Fluid } \\
\text { Used,BBL }\end{array}$} & \multicolumn{4}{|c|}{ Cumulative Vol. Flowback Water, BBL } & \multirow{2}{*}{$\begin{array}{c}\text { Percent } \\
\text { Collected }\end{array}$} \\
\hline & & & 1 Day & 5 Days & 14 Days & 90 Days & \\
\hline $\mathbf{A}$ & Vertical & 40,046 & 3,950 & 10,456 & 15,023 & & 37.5 \\
\hline $\mathbf{B}$ & Vertical & 94,216 & 1,095 & 10,782 & 13,718 & 17,890 & 19.0 \\
\hline $\mathbf{C}$ & Horizontal & 146,226 & 3,308 & 9,652 & 15,991 & & 10.9 \\
\hline $\mathbf{D}$ & Horizontal & 21,144 & 2,854 & 8,077 & 9,938 & 11,185 & 52.9 \\
\hline $\mathbf{E}$ & Horizontal & 53,500 & 8,560 & 20,330 & 24,610 & 25,680 & 48.0 \\
\hline $\mathbf{F}$ & Horizontal & 77,995 & 3,272 & 10,830 & 12,331 & 17,413 & 22.3 \\
\hline G & Horizontal & 123,921 & 1,219 & 7,493 & 12,471 & 18,677 & 15.1 \\
\hline H & Vertical & 36,035 & 3,988 & 16,369 & 21,282 & 31,735 & 88.0 \\
\hline K & Horizontal & 70,774 & 5,751 & 8,016 & 9,473 & & 13.4 \\
\hline $\mathbf{M}$ & Horizontal & 99,195 & 16,419 & 17,935 & 19,723 & & 19.9 \\
\hline $\mathbf{N}$ & Vertical & 11,435 & 2,432 & 2,759 & 3,043 & 3,535 & 30.9 \\
\hline $\mathbf{O}$ & Horizontal & 96,706 & 5,131 & 19,202 & & & 19.8 \\
\hline $\mathbf{Q}$ & Vertical & 23,593 & 1,315 & 3,577 & 5,090 & & 21.6 \\
\hline $\mathbf{S}$ & Vertical & 16,460 & 2,094 & 7,832 & 9,345 & 10,723 & 65.1 \\
\hline
\end{tabular}


Table B. 2 Concentration of total dissolved solids (TDS) in flowback water at 19 locations.

\begin{tabular}{|c|c|c|c|c|c|}
\hline Location & Day 0 & Day 1 & Day 5 & Day 14 & Day 90 \\
\hline $\mathbf{A}$ & 990 & 15,400 & 54,800 & 105,000 & 216,000 \\
\hline B & 27,800 & 22,400 & 87,800 & 112,000 & 194,000 \\
\hline C & 719 & 24,700 & 61,900 & 110,000 & 267,000 \\
\hline D & 1,410 & 9,020 & 40,700 & & 155,000 \\
\hline $\mathbf{E}$ & 5,910 & 28,900 & 55,100 & 124,000 & \\
\hline $\mathbf{F}$ & 462 & 61,200 & 116,000 & 157,000 & \\
\hline G & 1,920 & 74,600 & 125,000 & 169,000 & \\
\hline H & 7,080 & 19,200 & 150,000 & 206,000 & 345,000 \\
\hline I & 265 & 122,000 & 238,000 & 261,000 & \\
\hline $\mathbf{J}$ & 4,840 & 5,090 & 48,700 & 19,100 & \\
\hline K & 804 & 18,600 & 39,400 & 3,010 & \\
\hline $\mathbf{L}$ & 221 & 20,400 & 72,700 & 109,000 & \\
\hline M & 371 & & & 228,000 & \\
\hline $\mathbf{N}$ & 735 & 31,800 & 116,000 & & \\
\hline $\mathbf{O}$ & 2,670 & 17,400 & 125,000 & 186,000 & \\
\hline $\mathbf{P}$ & 401 & 11,600 & 78,600 & 63,900 & \\
\hline $\mathbf{Q}$ & 311 & 16,600 & 38,500 & 120,000 & \\
\hline $\mathbf{R}$ & 481 & 15,100 & 46,900 & 20,900 & \\
\hline S & 280 & 680 & 58,300 & 124,000 & \\
\hline
\end{tabular}




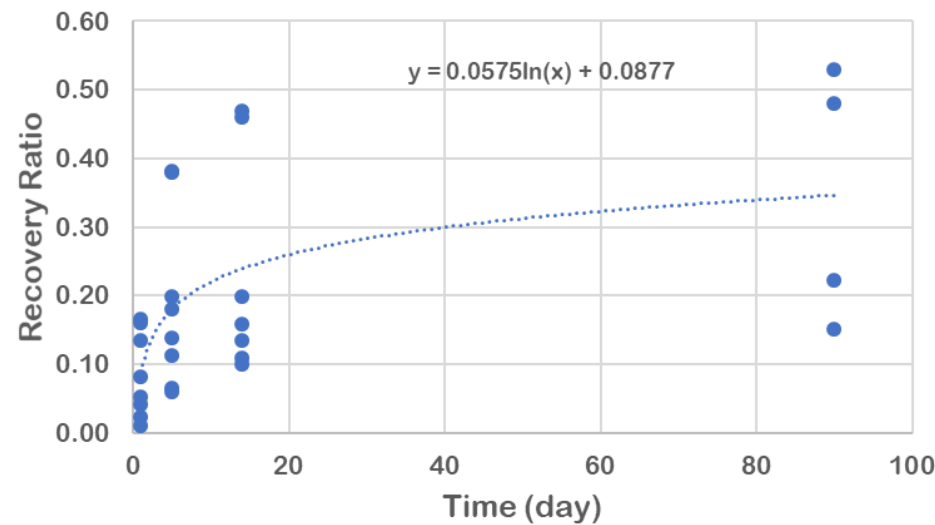

Figure B. 1 Cumulative recovery ratio of flowback water

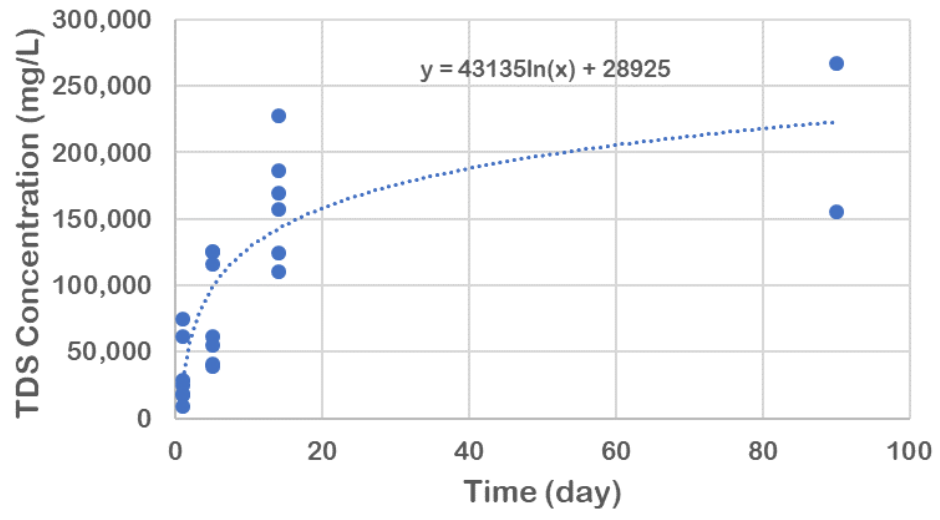

Figure B. 2 TDS concentration profile of flowback water 
Table B. 3 Flowrate and TDS weight fraction profiles for given injected fracturing fluid volume.

\begin{tabular}{|c|c|c|c|c|c|c|c|c|c|c|c|}
\hline \multirow{2}{*}{$\begin{array}{c}\text { Time } \\
(\text { month) }\end{array}$} & \multicolumn{7}{|c|}{ Volume of Injected Fracturing Fluid (BBL) } \\
\cline { 2 - 11 } & $\mathbf{5 0 , 0 0 0}$ & \multicolumn{2}{|c|}{$\mathbf{6 0}, \mathbf{0 0 0}$} & \multicolumn{2}{|c|}{$\mathbf{7 0 , 0 0 0}$} & $\mathbf{8 0 , 0 0 0}$ & $\mathbf{9 0 , 0 0 0}$ \\
\cline { 2 - 11 } & \multicolumn{2}{|c|}{ Flowrate (kg/s) and TDS Weight Fraction Profiles of Wastewater Recovered } \\
\cline { 2 - 12 } & $\mathbf{F}$ & $\mathbf{C}$ & $\mathbf{F}$ & $\mathbf{C}$ & $\mathbf{F}$ & $\mathbf{C}$ & $\mathbf{F}$ & $\mathbf{C}$ & $\mathbf{F}$ & $\mathbf{C}$ \\
\hline $\mathbf{1}$ & 26.1 & 0.084 & 31.3 & 0.084 & 36.5 & 0.084 & 41.7 & 0.084 & 46.9 & 0.084 \\
\hline $\mathbf{2}$ & 3.67 & 0.191 & 4.40 & 0.191 & 5.13 & 0.191 & 5.86 & 0.191 & 6.60 & 0.191 \\
\hline $\mathbf{3}$ & 2.14 & 0.215 & 2.57 & 0.215 & 3.00 & 0.215 & 3.43 & 0.215 & 3.86 & 0.215 \\
\hline $\mathbf{4}$ & 1.52 & 0.229 & 1.83 & 0.229 & 2.13 & 0.229 & 2.43 & 0.229 & 2.74 & 0.229 \\
\hline $\mathbf{5}$ & 1.18 & 0.240 & 1.42 & 0.240 & 1.65 & 0.240 & 1.89 & 0.240 & 2.12 & 0.240 \\
\hline $\mathbf{6}$ & 0.96 & 0.249 & 1.16 & 0.250 & 1.35 & 0.249 & 1.54 & 0.250 & 1.74 & 0.249 \\
\hline $\mathbf{7}$ & 0.82 & 0.256 & 0.98 & 0.256 & 1.14 & 0.256 & 1.30 & 0.256 & 1.47 & 0.256 \\
\hline $\mathbf{8}$ & 0.71 & 0.263 & 0.85 & 0.263 & 0.99 & 0.263 & 1.13 & 0.263 & 1.27 & 0.263 \\
\hline $\mathbf{9}$ & 0.62 & 0.268 & 0.75 & 0.268 & 0.87 & 0.268 & 1.00 & 0.268 & 1.12 & 0.268 \\
\hline $\mathbf{1 0}$ & 0.56 & 0.273 & 0.67 & 0.273 & 0.78 & 0.273 & 0.89 & 0.273 & 1.00 & 0.273 \\
\hline $\mathbf{1 1}$ & 0.50 & 0.277 & 0.60 & 0.277 & 0.71 & 0.277 & 0.81 & 0.277 & 0.91 & 0.277 \\
\hline $\mathbf{1 2}$ & 0.46 & 0.281 & 0.55 & 0.281 & 0.64 & 0.281 & 0.74 & 0.281 & 0.83 & 0.281 \\
\hline
\end{tabular}




\section{APPENDIX C}

WASTEWATER MANAGEMENT MODEL

Table C. 1 Parameters and cost-coefficients used in the TMD system and wastewater management.

\begin{tabular}{|c|c|}
\hline Parameter & Value \\
\hline Operation time (s/day) & 86400 \\
\hline Annualize factor (1/year) & 0.1 \\
\hline $\begin{array}{l}\text { Unit transportation cost from fractured well to } \\
\text { wastewater storage }(\$ / \mathrm{kg})\end{array}$ & 0.00036 \\
\hline $\begin{array}{c}\text { Unit transportation cost from wastewater storage to } \\
\text { TMD system }(\$ / \mathrm{kg})\end{array}$ & 0.00036 \\
\hline $\begin{array}{l}\text { Unit transportation cost from TMD system to reused } \\
\text { water tank }(\$ / \mathrm{kg})\end{array}$ & 0.00141 \\
\hline $\begin{array}{l}\text { Unit transportation cost from TMD system to rejected } \\
\text { water tank }(\$ / \mathrm{kg})\end{array}$ & 0.0083 \\
\hline Selling price of reused water $(\$ / \mathbf{k g})$ & 0.002 \\
\hline Disposal cost of rejected water $(\$ / \mathbf{k g})$ & 0.013 \\
\hline Fixed charge for wastewater storage (\$) & 10000 \\
\hline Fixed charge for reused water tank (\$) & 10000 \\
\hline Fixed charge for rejected water tank (\$) & 52000 \\
\hline Variable charge for wastewater storage $(\$ / \mathbf{k g})$ & 0.0063 \\
\hline Variable charge for reused water tank $(\$ / \mathbf{k g})$ & 0.0063 \\
\hline Variable charge for rejected water tank $(\$ / \mathbf{k g})$ & 0.0135 \\
\hline Maximum capacity for wastewater storage (kg) & 12000000 \\
\hline Maximum capacity for reused water tank (kg) & 12000000 \\
\hline Maximum capacity for rejected water tank (kg) & 20000000 \\
\hline
\end{tabular}


Table C. 1 Continued.

\begin{tabular}{|c|c|}
\hline Parameter & Value \\
\hline TMD feed temperature $(\mathbf{K})$ & 363 \\
\hline TMD permeate temperature (K) & 338 \\
\hline $\begin{array}{c}\text { Temperature-independent base value of membrane } \\
\text { permeability }\left(\mathbf{k g} / \mathbf{m} 2 / \mathbf{s} / \mathbf{p a} / \mathbf{K}^{\mathbf{1 . 3 3 4}}\right)\end{array}$ & $7.5 \times 10^{11}$ \\
\hline
\end{tabular}

Table C. 2 Design variables and costs for wastewater management in Case 1.

\begin{tabular}{|c|c|}
\hline Variable & Value \\
\hline Capacity of wastewater storage (kg) & $2.89 \times 10^{6}$ \\
\hline Capacity of reused water tank (kg) & $2.62 \times 10^{5}$ \\
\hline Capacity of rejected water tank (kg) & $2.31 \times 10^{5}$ \\
\hline Membrane area of TMD system $\left(\mathrm{m}^{2}\right)$ & 393 \\
\hline $\begin{array}{l}\text { Transportation cost from fractured well to wastewater } \\
\text { storage (\$/year) }\end{array}$ & 1,707 \\
\hline $\begin{array}{c}\text { Transportation cost from wastewater storage to TMD } \\
\text { system (\$/year) }\end{array}$ & 1,707 \\
\hline $\begin{array}{l}\text { Transportation cost from TMD system to reused water } \\
\text { tank (\$/year) }\end{array}$ & 4,152 \\
\hline $\begin{array}{c}\text { Transportation cost from TMD system to rejected } \\
\text { water tank (\$/year) }\end{array}$ & 14,904 \\
\hline Operating cost for TMD system (\$/year) & 16,694 \\
\hline Disposal cost (\$/year) & 23,942 \\
\hline Capital cost for storage unit (\$/year) & 2,822 \\
\hline Capital cost for reuse unit (\$/year) & 1,165 \\
\hline Capital cost for disposal unit (\$/year) & 5,512 \\
\hline Capital cost for treatment unit (\$/year) & 28,066 \\
\hline
\end{tabular}


Table C. 2 Continued.

\begin{tabular}{|c|c|}
\hline Variable & Value \\
\hline Profit from reusing water (\$/year) & 5,890 \\
\hline TOC (\$/year) & 63,106 \\
\hline TCC (\$/year) & 37,565 \\
\hline TAC (\$/year) & 94,781 \\
\hline
\end{tabular}

Table C. 3 Flowrate (kg/s) and TDS weight fraction of the streams in Case 1.

\begin{tabular}{|c|c|c|c|c|c|c|c|c|c|c|c|c|}
\hline $\begin{array}{c}\text { Time } \\
\text { (month) }\end{array}$ & 1 & 2 & 3 & 4 & 5 & 6 & 7 & 8 & 9 & 10 & 11 & 12 \\
\hline$F^{\text {well_out }}$ & 36.5 & 5.13 & 3.00 & 2.13 & 1.65 & 1.35 & 1.14 & 0.99 & 0.87 & 0.78 & 0.71 & 0.64 \\
\hline$C^{\text {well_out }}$ & 0.084 & 0.191 & 0.215 & 0.229 & 0.240 & 0.249 & 0.256 & 0.263 & 0.268 & 0.273 & 0.277 & 0.281 \\
\hline$F^{\text {storage_in }}$ & 36.5 & 5.13 & 3.00 & 2.13 & 1.65 & 1.35 & 1.14 & 0.99 & 0.87 & 0.78 & 0.71 & 0.64 \\
\hline$C^{\text {storage_in }}$ & 0.084 & 0.191 & 0.215 & 0.229 & 0.240 & 0.249 & 0.256 & 0.263 & 0.268 & 0.273 & 0.277 & 0.281 \\
\hline$F^{\text {storage_out }}$ & 3.98 & 4.14 & 4.25 & 4.34 & 4.43 & 4.50 & 4.58 & 4.67 & 4.76 & 4.88 & 5.03 & 5.30 \\
\hline C $^{\text {storage_out }}$ & 0.084 & 0.098 & 0.108 & 0.115 & 0.122 & 0.128 & 0.134 & 0.140 & 0.146 & 0.153 & 0.162 & 0.177 \\
\hline$F^{\text {treat_in }}$ & 3.98 & 4.14 & 4.25 & 4.34 & 4.43 & 4.50 & 4.58 & 4.67 & 4.76 & 4.88 & 5.03 & 5.30 \\
\hline$C^{\text {treat_in }}$ & 0.084 & 0.098 & 0.108 & 0.115 & 0.122 & 0.128 & 0.134 & 0.140 & 0.146 & 0.153 & 0.162 & 0.177 \\
\hline$F^{\text {reuse_in }}$ & 3.03 & 2.98 & 2.94 & 2.91 & 2.88 & 2.86 & 2.83 & 2.81 & 2.78 & 2.74 & 2.70 & 2.63 \\
\hline$C^{\text {reuse_in }}$ & 0 & 0 & 0 & 0 & 0 & 0 & 0 & 0 & 0 & 0 & 0 & 0 \\
\hline$F^{\text {disposal_in }}$ & 0.95 & 1.16 & 1.31 & 1.43 & 1.54 & 1.65 & 1.75 & 1.86 & 1.99 & 2.13 & 2.33 & 2.67 \\
\hline$C^{\text {disposal_in }}$ & 0.350 & 0.350 & 0.350 & 0.350 & 0.350 & 0.350 & 0.350 & 0.350 & 0.350 & 0.350 & 0.350 & 0.350 \\
\hline
\end{tabular}


Table C. 4 Design variables and costs for wastewater management in Case 2.

\begin{tabular}{|c|c|}
\hline Variable & Value \\
\hline Capacity of wastewater storage 1 (kg) & $5.21 \times 10^{6}$ \\
\hline Capacity of wastewater storage 2 (kg) & $1.20 \times 10^{7}$ \\
\hline Capacity of reused water tank (kg) & $1.5728 \times 10^{6}$ \\
\hline Capacity of rejected water tank (kg) & $9.4849 \times 10^{5}$ \\
\hline Membrane area of TMD system $\left(\mathrm{m}^{2}\right)$ & 2357.5 \\
\hline $\begin{array}{l}\text { Transportation cost from fractured well to wastewater } \\
\text { storage (\$/year) }\end{array}$ & 10,239 \\
\hline $\begin{array}{l}\text { Transportation cost from wastewater storage to TMD } \\
\text { system (\$/year) }\end{array}$ & 10,239 \\
\hline $\begin{array}{l}\text { Transportation cost from TMD system to reused water } \\
\text { tank (\$/year) }\end{array}$ & 24,913 \\
\hline $\begin{array}{c}\text { Transportation cost from TMD system to rejected } \\
\text { water tank (\$/year) }\end{array}$ & 89,423 \\
\hline Operating cost for TMD system (\$/year) & 100,170 \\
\hline Disposal cost (\$/year) & 143,650 \\
\hline Capital cost for storage unit (\$/year) & 12,841 \\
\hline Capital cost for reuse unit (\$/year) & 1,991 \\
\hline Capital cost for disposal unit (\$/year) & 6,480 \\
\hline Capital cost for treatment unit (\$/year) & 168,500 \\
\hline Profit from reusing water (\$/year) & 35,338 \\
\hline TOC (\$/year) & 378,630 \\
\hline TCC (\$/year) & 189,820 \\
\hline TAC (\$/year) & 533,112 \\
\hline
\end{tabular}


Table C. 5 Flowrate (kg/s) and TDS weight fraction of the streams in Case 2.

\begin{tabular}{|c|c|c|c|c|c|c|c|c|c|c|c|c|}
\hline $\begin{array}{c}\text { Time } \\
\text { (month) }\end{array}$ & 1 & 2 & 3 & 4 & 5 & 6 & 7 & 8 & 9 & 10 & 11 & 12 \\
\hline$F^{\text {well_out }}$ & 218.8 & 30.8 & 18.0 & 12.8 & 9.9 & 8.1 & 638 & 5.9 & 5.2 & 4.7 & 4.2 & 3.9 \\
\hline$C^{\text {well_out }}$ & 0.084 & 0.191 & 0.215 & 0.229 & 0.240 & 0.249 & 0.256 & 0.263 & 0.268 & 0.273 & 0.277 & 0.281 \\
\hline$F^{\text {storage1_in }}$ & 56.10 & 30.60 & 16.38 & 6.39 & 1.25 & 0.16 & 5.28 & 4.85 & 4.50 & 4.21 & 3.96 & 0.64 \\
\hline$C^{\text {storage1_in }}$ & 0.084 & 0.191 & 0.215 & 0.229 & 0.240 & 0.249 & 0.256 & 0.263 & 0.268 & 0.273 & 0.277 & 0.281 \\
\hline$F^{\text {storage1_out }}$ & 0.084 & 26.33 & 26.06 & 21.56 & 19.33 & 17.51 & 5.28 & 4.85 & 4.50 & 4.21 & 3.96 & 0.64 \\
\hline$C^{\text {storage1_out }}$ & 0.084 & 0.122 & 0.141 & 0.151 & 0.154 & 0.155 & 0.256 & 0.263 & 0.268 & 0.273 & 0.277 & 0.281 \\
\hline$F^{\text {storage2_in }}$ & 162.73 & 0.19 & 1.63 & 6.39 & 8.66 & 7.94 & 1.57 & 1.08 & 0.73 & 0.47 & 0.28 & 3.22 \\
\hline$C^{\text {storage2_in }}$ & 0.084 & 0.191 & 0.215 & 0.229 & 0.240 & 0.249 & 0.256 & 0.263 & 0.268 & 0.273 & 0.277 & 0.281 \\
\hline$F^{\text {storage2_out }}$ & 23.84 & 0.19 & 1.82 & 6.32 & 8.55 & 10.37 & 22.60 & 23.03 & 23.38 & 23.67 & 23.92 & 27.23 \\
\hline$C^{\text {storage2_out }}$ & 0.084 & 0.084 & 0.085 & 0.092 & 0.100 & 0.108 & 0.110 & 0.112 & 0.113 & 0.114 & 0.115 & 0.134 \\
\hline$F^{\text {treat_in }}$ & 23.93 & 26.53 & 27.88 & 27.88 & 27.88 & 27.88 & 27.88 & 27.88 & 27.88 & 27.88 & 27.88 & 27.88 \\
\hline$C^{\text {treat_in }}$ & 0.084 & 0.121 & 0.138 & 0.138 & 0.138 & 0.138 & 0.138 & 0.138 & 0.138 & 0.138 & 0.138 & 0.138 \\
\hline$F^{\text {reuse_in }}$ & 18.20 & 17.33 & 16.90 & 16.90 & 16.90 & 16.90 & 16.90 & 16.90 & 16.90 & 16.90 & 16.90 & 16.90 \\
\hline Creuse_in $^{\text {reuse }}$ & 0 & 0 & 0 & 0 & 0 & 0 & 0 & 0 & 0 & 0 & 0 & 0 \\
\hline$F^{\text {disposal_in }}$ & 5.72 & 9.20 & 10.98 & 10.98 & 10.98 & 10.98 & 10.98 & 10.98 & 10.98 & 10.98 & 10.98 & 10.98 \\
\hline$C^{\text {disposal_in }}$ & 0.350 & 0.350 & 0.350 & 0.350 & 0.350 & 0.350 & 0.350 & 0.350 & 0.350 & 0.350 & 0.350 & 0.350 \\
\hline
\end{tabular}




\section{APPENDIX D}

ONE-WING HYDRAULIC FRACTURE MODEL

Table D. 1 Parameters used for one-wing fracture in Marcellus Shale.

\begin{tabular}{|c|c|}
\hline Parameter & Value \\
\hline Dimension; Length (m) $\times$ width (m) $\times$ height $\mathbf{( m )}$ & $29.26 \times 135 \times 60$ \\
\hline Initial reservoir pressure (psi) & 5,024 \\
\hline Reservoir temperature (F) & 0.45 \\
\hline Initial gas saturation & $3 \times 10^{6}$ \\
\hline Total compressibility (psi $\left.{ }^{-1}\right)$ & 0.0001 \\
\hline Matrix permeability (md) & 0.046 \\
\hline Matrix porosity & 120 \\
\hline Propped fracture half-length (m) & 0.0029 \\
\hline Propped fracture width (m) & 60 \\
\hline Propped fracture height (m) & 55 \\
\hline Number of fractures per well & \\
\hline
\end{tabular}

Table D. 2 Shale gas production and corresponding revenue for the first production year.

\begin{tabular}{|c|c|c|c|c|}
\hline $\begin{array}{c}\text { Half-fracture } \\
\text { length (m) }\end{array}$ & $\begin{array}{c}\text { Production for } \\
\text { half-fracture } \\
\text { (FT }^{\mathbf{3}} / \text { year) }\end{array}$ & $\begin{array}{c}\text { Production for } \\
\text { one shale well } \\
\text { (MMFT }^{\mathbf{3}} / \\
\text { year) }\end{array}$ & $\begin{array}{c}\text { Revenue for } \\
\text { half-fracture } \\
\text { (\$/year) }\end{array}$ & $\begin{array}{c}\text { Revenue for } \\
\text { one shale well } \\
\text { (MM\$/year) }\end{array}$ \\
\hline $\mathbf{1 0 5}$ & $7,987,888$ & 879 & 23,073 & 2.54 \\
\hline $\mathbf{1 1 0}$ & $8,365,435$ & 920 & 24,164 & 2.66 \\
\hline $\mathbf{1 1 5}$ & $8,742,476$ & 962 & 25,253 & 2.78 \\
\hline
\end{tabular}


Table D. 2 Continued.

\begin{tabular}{|c|c|c|c|c|}
\hline $\begin{array}{c}\text { Half-fracture } \\
\text { length }(\mathbf{m})\end{array}$ & $\begin{array}{c}\text { Production for } \\
\text { half-fracture } \\
\text { (FT }\end{array}$ & $\begin{array}{c}\text { Production for } \\
\text { one shar) } \\
\text { (MMFT }^{\mathbf{3}} / \\
\text { year) }\end{array}$ & $\begin{array}{c}\text { Revenue for } \\
\text { half-fracture } \\
\text { (\$/year) }\end{array}$ & $\begin{array}{c}\text { Revenue for } \\
\text { one shale well } \\
\text { (MM } \$ \text { /year) }\end{array}$ \\
\hline $\mathbf{1 2 0}$ & $9,120,033$ & 1,003 & 26,344 & 2.90 \\
\hline
\end{tabular}

